\title{
The performance of non-invasive tests to rule-in and rule-out significant coronary artery stenosis in patients with stable angina: A meta-analysis focused on post-test disease probability
}

Prof. Juhani Knuuti MD, $\mathrm{PhD}^{1}$, Haitham Ballo* $\mathrm{MD}^{1}$, Luis Eduardo Juarez-Orozco* MD, $\mathrm{PhD}^{1}$, Antti Saraste MD, $\mathrm{PhD}^{1}$, Prof. Philippe Kolh $\mathrm{MD}, \mathrm{PhD}^{2}$, Anne Wilhelmina Saskia Rutjes $\mathrm{PhD}^{3}$, Prof. Peter Jüni MD, $\mathrm{PhD}^{4}$, Prof. Stephan Windecker MD, $\mathrm{PhD}^{5}$, Prof. Jeroen J Bax $\mathrm{MD}, \mathrm{PhD}^{6}$, Prof. William Wijns $\mathrm{MD}, \mathrm{PhD}^{7}$

*These authors made an equal contribution to the manuscript

Affiliations:

1. Turku PET Centre, Turku University Hospital and University of Turku, Kiinamyllynkatu 4-8, 20520, Turku, Finland

2. Department of Biomedical and Preclinical Sciences, University of Liège, Sart Tilman B 35, 4000, Liège, Belgium

3. Institute of Social and Preventive Medicine (ISPM), University of Bern, Mittelstrasse 43, 3012, Bern, Switzerland and Institute of Primary Health Care (BIHAM), University of Bern, Gesellschaftsstrasse 49, 3012, Bern, Switzerland

4. Department of Medicine, Applied Health Research Centre (AHRC), Li Ka Shing Knowledge Institute of St. Michael's Hospital, Institute of Health Policy, Management and Evaluation, University of Toronto, 30 Bond St, ON M5B 1W8, Toronto, Canada

5. Department of Cardiology, University Hospital Bern, Freiburgstrasse 4, 3010, Bern, Switzerland

6. Department of Cardiology, Leiden University Medical Center, Albinusdreef 2, 2333ZA, Leiden, The Netherlands

7. The Lambe Institute for Translational Medicine and Curam, National University of Ireland, Galway and Saolta University Healthcare Group, University College Hospital Galway, Newcastle Rd, Galway, Ireland

\section{Corresponding Author:}

Prof. Juhani Knuuti MD, PhD

Director of the Turku PET Centre

clo Turku University Hospital

P.O. Box 52, 20521 Turku, Finland

Email: Juhani.Knuuti@utu.fi

Phone: +35823132842

Fax: +35822318191 


\section{Abbreviations}

CAD Coronary artery disease

CCTA Coronary computed tomography angiography

CMR Cardiovascular magnetic resonance

ICA Invasive coronary angiography

IVUS Intravascular ultrasound

OCT Optical coherence tomography

PET Positron emission tomography

PTP Pre-test probability

QCA Quantitative coronary angiography

SPECT Single photon emission computed tomography 


\section{ABSTRACT}

Aims

To determine the ranges of pre-test probability (PTP) of CAD in which stress ECG, stress echocardiography, coronary computed tomography angiography (CCTA), single-photon emission computed tomography (SPECT), positron emission tomography (PET) and cardiac magnetic resonance (CMR) can reclassify patients into a post-test probability that defines $(>85 \%)$ or excludes $(<15 \%)$ anatomically (defined by visual evaluation of invasive coronary angiography [ICA]) and functionally (defined by a fractional flow reserve $[\mathrm{FFR}] \leq 0.80$ ) significant CAD.

\section{Methods and Results}

A broad search in electronic databases until August 2017 was performed. Studies on the aforementioned techniques in $>100$ patients with stable CAD that utilized either ICA or ICA with FFR measurement as reference, were included. Study-level data was pooled using a hierarchical bivariate random-effects model and likelihood ratios were obtained for each technique. The PTP ranges for each technique to rule-in or rule-out significant CAD were defined. 28,664 patients from 132 studies that used ICA as reference and 4,131 from 23 studies using FFR, were analyzed.

Stress ECG can rule-in and rule-out anatomically significant CAD only when PTP is $\geq 80 \%[76,83]$ and $\leq 19 \%[15,25]$, respectively. CCTA is able to rule-in anatomic CAD at a PTP $\geq 58 \%[45,70]$ and rule-out at a PTP $\leq 80 \%[65,94]$. The corresponding PTP values for functionally significant CAD were $\geq 75 \%[67,83]$ and $\leq 57 \%[40,72]$ for CCTA, and $\geq 71 \%[59,81]$ and $\leq 27[24,31]$ for ICA, demonstrating poorer performance of anatomic imaging against FFR. In contrast, functional imaging techniques (PET, stress CMR and SPECT) are able to rule-in functionally significant CAD when PTP is $\geq 46-59 \%$ and rule-out when PTP is $\leq 34-57 \%$.

\section{Conclusion}

The various diagnostic modalities have different optimal performance ranges for the detection of anatomically and functionally significant CAD. Stress ECG appears to have very limited diagnostic power. The selection of a diagnostic technique for any given patient to rule-in or rule-out CAD should be based on the optimal PTP range for each test and on the basis of the assumed reference standard. 
Keywords: Stable coronary artery disease, non-invasive imaging, pre-test probability, post-test probability, likelihood ratio 


\section{INTRODUCTION}

Accurate detection of coronary artery disease (CAD) remains paramount in the practice of cardiology. Traditionally, the characterization of "significant" CAD has relied upon visual evaluation of coronary artery stenosis during invasive coronary angiography (ICA). However, the severity of angiographic stenosis does not unequivocally reflect its functional significance.(1) Recently, the invasive assessment of fractional flow reserve (FFR) has been adopted to identify functionally significant coronary artery stenoses.(2) Yet, FFR evaluation is not without limitations as diffuse CAD and hemodynamic conditions have shown an influence on its estimation, it is inherently invasive and costly, and it still does not represent the most common practice in invasive evaluation of CAD.(3)

Stable CAD is understood as the condition characterized by episodes of inducible and reversible ischemia commonly associated with transient chest discomfort. The current European and American guidelines on the management of stable $\mathrm{CAD}(2,4)$ recommend that patients with an intermediate pre-test probability (PTP) (ranging from 15 to $85 \%$ ) of significant CAD should undergo non-invasive evaluation(5,6). In subjects whose probability of a significant coronary artery narrowing is low $(<15 \%)$, routine testing is not recommended. On the other hand, patients with a high probability (>85\%) of the disease calls for direct therapeutic interventions.

In the group of patients with intermediate PTP of significant CAD, the current recommendations for the selection of the optimal non-invasive technique are broad and do not assign preference of one modality over another. Certain techniques are broadly available because of their relative low technical and personnel demands (such as stress ECG) or good availability (stress echocardiography, coronary computed tomography angiography [CCTA], and single-photon emission computed tomography [SPECT]), while others, like positron emission tomography (PET) and stress cardiac magnetic resonance (CMR), although 
powerful, are much less available and their applicability is still limited by infrastructural and capacity requirements (7).

It is expected that each technique has a particular range of PTP of significant CAD where the usefulness of its application is maximized. The performance of non-invasive techniques is generally reported in terms of sensitivity and specificity. Nevertheless, these numbers cannot be readily utilized in the clinical decision-making process. They can however be used to derive positive and negative likelihood ratios (LR+ and LR-), which constitute readily useful parameters of a test's accuracy that facilitate the selection of a diagnostic test for individual patients.(8) Given a PTP of significant CAD and the performance of a particular test by means of its LR's, one can assess the post-test probability of significant CAD after performing such test. Using this approach, one can estimate the range of PTP when a positive or negative test result can confidently rule-in (if the post-test probability goes beyond $85 \%$ ) or rule-out (if the post-test probability drops below 15\%) the disease.

As currently both anatomical (ICA) and functional (FFR) reference standards are utilized, it is rational to consider evidence using both standards.(9) The anatomical standard has been used in most of the studies available today and there is a massive amount of evidence, although functional information has gained increasing interest. It can be expected that some tests demonstrate better agreement with ICA while others with FFR. Therefore, integration of all available data may provide important clinical information for conscious selection of the tests.

The aim of the present systematic review and meta-analysis was to evaluate the diagnostic performance of stress ECG, stress echocardiography, CCTA, SPECT, PET, stress CMR, and ICA in the detection of anatomically and functionally significant CAD in order to determine the optimal range of PTP in the diagnostic application of each technique for rulingin or ruling-out significant CAD. 


\section{METHODS}

The present systematic review was conducted in accordance to the Preferred Reporting items for Systematic Reviews and Meta-analysis (PRISMA)(10) recommendations and the MOOSE checklist (see results and e-Table 1 in the supplement).(11)

\section{Data Sources}

We performed a systematic search for original studies published until August 2017 that reported on the diagnostic performance of stress ECG, stress echocardiography, CCTA, SPECT, PET, stress CMR, and ICA for the detection of significant CAD.

The search was performed in electronic databases (Medline, Embase, PubMed, Scopus, The Cochrane Library, Web of Science, ProQuest) using a broad strategy with a combination of MeSH terms and free text words sensitive to: identify studies concerning 1) the aforementioned diagnostic techniques, 2) diagnostic performance, 3) patients with intermediate pre-test probability of the condition, and 4) significant CAD. The search results were limited to the English language and to studies performed in humans. The full search string is reported in e-Table 2. Reference lists from relevant studies were scanned and crosschecked to identify potentially overlooked publications.

\section{Study Selection and Quality Assessment}

Studies were included according to the following eligibility criteria: 1) the study aimed to investigate stable CAD (not acute coronary syndromes), 2) either catheter-based X-ray angiography (ICA) or ICA with FFR evaluation were used as the reference standard for the diagnosis of stable CAD, 3) the reported data was explicit or sufficient to extract numbers for true and false positive and negative results, and 4) the study included a sample of at least 100 patients (for robustness). Selected studies were further divided according to the reference standard considered (ICA or FFR evaluation). 
For each included study, the Quality Assessment of Diagnostic Accuracy Studies (QUADAS-2) criteria were determined by two authors (LJ and HB). The QUADAS-2 tool assesses the study quality in different domains including patient selection, index test, reference standard, and flow of patients through the study considering the timing of the index test and reference standard. For each article, quality and applicability were assessed in the aforementioned domains as follows: "yes" if concern existed based on enough description in the report, "no" if there was no concern based on enough description in the report or "unclear" if there was inadequate or insufficient information reported in the article to make a judgment.

\section{Data Extraction}

Data were recorded according to the technique and reference standard utilized. The number of subjects, male to female patient proportion, age, type of stressor, tracer utilized (if any), stable CAD definition, and prevalence were extracted. The number of true positives (TP), false positives (FP), true negatives (TN), and false negatives (FN), as well as derived diagnostic performance variables were recorded.

Study review, quality evaluation, and data extraction were performed in parallel by two authors (AS and HB). Any specific discrepancies were resolved by consensus. If necessary, a third reviewer (JK) was considered to reach convergence.

\section{Reference Standard}

Catheter-based ICA alone and ICA with FFR measurement were considered as the reference standards for the determination of anatomically significant and functionally significant $\mathrm{CAD}$, respectively. Anatomic coronary narrowing $>50 \%$ was considered as determinant of significant $\mathrm{CAD}$ and an $\mathrm{FFR} \leq 0.80$ was considered as functionally significant CAD.

Data synthesis and statistical analysis 
Hierarchical bivariate random-effects models were constructed to combine individual study-level data on the sensitivities and specificities across studies. This model takes the correlation between sensitivity and specificity into account, and is described in detail elsewhere.(12) The bivariate model used parametrization to render summary points for sensitivity and specificity with $95 \%$ confidence intervals $[\mathrm{CI}]$ for each of the imaging techniques. We used an unstructured covariance matrix allowing all variances and covariances to be distinct. We then derived summary estimates of the LR+ and LR-with their confidence intervals from the model estimates. For echocardiography and SPECT, more than one type of stressor was used. We compared if a model distinguishing by type of stressor had a better model fit than a model grouping all stressor techniques together. The analysis was performed separately for anatomically and functionally significant CAD (according to the reference standard used). We used the p-value from the likelihood ratio test to determine if the model with a covariate for the type of stressor fitted the data better than a model without such covariate. If the p-value was 0.05 or less, we depicted summary estimates for a specific type of stressor.

\section{Utility of non-invasive approaches according to pre-test probability of stable CAD}

Once the positive and negative LRs of each non-invasive diagnostic technique were obtained for both accepted reference standards, the ranges and in which every single technique allows to confidently rule-in $\mathrm{CAD}$, rule-out $\mathrm{CAD}$, or both were input into a colorcoded graph. Additionally, we created a supplemental color-coded suggestion over the structure of the current ESC guidelines stable CAD PTP table to depict the suggested utility of each diagnostic technique at each level of risk based on age, sex, and type of symptoms. 


\section{RESULTS}

\section{Study Characteristics}

The study selection flow chart is shown in Figure 1. Specific characteristics and the full reference for each selected study can be consulted in e-Table 3 in the Supplement. After eligibility assessment and technique subgroup characterization, 13 studies on stress ECG, 12 studies on exercise stress echocardiography, 30 on dobutamine stress echocardiography, 9 studies on CCTA, 28 studies on exercise \& adenosine or dipyridamole stress SPECT, 13 on exercise stress SPECT, 3 studies on PET, and 11 on stress CMR were considered for the pooled analysis on anatomically significant CAD. On the other hand, 2 studies in ICA, 7 studies on CCTA, 5 on exercise stress SPECT, 4 on PET, and 5 on stress CMR were considered for the pooled analysis on functionally significant CAD.

\section{Study Heterogeneity and Quality}

Risk of bias in the included studies, as assessed with the QUADAS-2 score, showed important variation across diagnostic modalities. Overall, PET, CCTA, and stress CMR showed a low risk of bias and therefore, did not raise substantial concerns of applicability. However, these modalities conveyed the smallest number of studies included. Conversely, the proportions of unclear ratings for ECG and echocardiography studies related to the year when these were performed. For the oldest studies, insufficient data for this assessment is commonly reported. SPECT studies generally rated less well showing a balanced proportion of unclear and high risk of bias in all domains. E-Figure 1 in the Supplement shows this assessment across techniques in an ascending order of risk. Overall quality per type of reference standard is shown in Figure 2.

\section{Performance Estimates}

The pooled analysis considering anatomically significant CAD included a total of 2,442 patients for stress ECG, 4,302 for stress echo (with exercise or vasodilator), 2,756 for 
CCTA, 4,346 for exercise stress SPECT, 6,551 for exercise \& adenosine or dipyridamole stress SPECT, 418 for PET, and 3,393 for stress CMR. Further, the pooled analysis considering functionally significant CAD included 954 for ICA, 1,140 patients for CCTA, 740 for exercise stress SPECT, 709 for PET, and 588 for stress CMR. Some studies evaluated several techniques or technique subgroups simultaneously. Such studies were included as independent entries in more than one pooled analysis per technique.

Table 1 summarizes the performance estimates for every diagnostic technique according to each reference standard. Some techniques had various subcategories typically according to the type of stressor utilized. Some of these subcategories are less commonly used or did not yield adequate information for a summary estimate (e.g. stress echo with dobutamine stress $n=30$, dobutamine stress SPECT $n=2$, and dobutamine stress CMR $n=2$ ) and were not included in these estimates.

Considering anatomically significant CAD, there were 11 vasodilatory stress echocardiography studies and analysis considering $>50 \%$ as significant stenosis yielded a sensitivity of $0.75[0.70,0.80]$ and specificity of $0.91[0.86,0.94]$. These summary estimates were not statistically different from the summary estimates obtained for exercise stress echo (likelihood ratio test $p$-value $=0.386$ ) and were consequently pooled together. The summary estimates obtained from 27 dobutamine stress echocardiography studies were 0.81 [0.77, $0.85]$ for sensitivity and $0.84[0.81,0.87]$ for specificity and given that these estimates were significantly different from exercise stress echocardiography (likelihood ratio test $p$ value $=0.012$ ), they were not pooled together but their references can be consulted in the supplementary material.

When anatomically significant CAD was used as reference standard, the LR- of different tests varied from 0.04 to 0.68 . The best performance in ruling out CAD was achieved using CCTA and poorest with stress ECG. The LR+ varied from 1.53 to 5.87. The best 
performance for ruling in CAD was achieved using PET and the poorest with stress ECG. The LR+ and LR- for dobutamine stress echocardiography subgroup were $8.03[4.98,12.95]$ and $0.27[0.22,0.34]$, respectively (not shown in the tables).

When functionally significant CAD was considered as reference standard, LR-varied from 0.13 to 0.44 . CCTA, PET, and stress CMR had the best and similar performance in ruling out significant CAD (-LR=0.13 [0.07, 0.24]), while interestingly, ICA had the poorest. The $\mathrm{LR}+$ of the available techniques varied from 1.97 to 7.10 . The poorest performances in ruling-in an abnormal FFR were documented for CCTA (LR+=1.97 [1.28, 3.03]) and ICA $(\mathrm{LR}+=2.49[1.47,4.21])$, while functional imaging tests conversely demonstrated the best performance (LR+ range: 3.87-7.1). We could not identify enough robust studies to pool estimates for stress ECG and stress echocardiography.

\section{Effectiveness of non-invasive diagnostic techniques in ruling in/out significant CAD}

The Fagan nomogram is a useful tool to graphically apply LRs to a PTP to calculate the post-test probability. A parallel example of its use is depicted in Figure 3, which shows how one can calculate the post-test probabilities after a positive or negative test result starting from any PTP in an individual patient.

The same nomogram can be also utilized backwards so that we can assess the PTP values that will lead to a defined range of post-test probability for each diagnostic method. Therefore, using the data from the meta-analysis, we defined the ranges of PTP of CAD where the diagnostic techniques can confidently rule-in (by driving the post-test probability above $85 \%$ ) and/or rule-out (by driving the post-test probability below 15\%) significant CAD. This was done separately for both anatomically and functionally significant CAD. Such ranges are schematically shown along with their corresponding upper and lower limits in Figure 4 and numerically reported in e-Table 4 in the Supplement. 
Finally, based on the obtained data described above, we transformed the PTP table from the 2013 ESC Guidelines on the management of stable coronary artery disease (4) into a supplemental guide that exemplifies how clinicians could implement the resulting estimates of performance in this report in order to select a diagnostic test that confidently rules-in or rulesout CAD (both anatomically and functionally significant CAD) at each patient PTP category (e-Figure 2 panels $\mathrm{A}$ and $\mathrm{B}$, respectively).

\section{DISCUSSION}

The present study analyzed the evidence on the performance of different diagnostic techniques for the detection of either anatomically or functionally significant CAD. Beyond reporting traditional metrics, we also portrayed their performance as LRs and defined the optimal ranges of PTP for each test where they can reclassify patients from intermediate to either low or high post-test probability of CAD (i.e. rule-out or rule-in, respectively).

From this analysis several main messages can be driven. Stress ECG appears to have very limited diagnostic power to rule-in or rule-out significant CAD. In fact, there was no single PTP value in which stress ECG can both define the diagnosis and exclude it. Moreover, even to confidently rule-out CAD, a very low PTP $(\leq 19 \%[15,25])$ is needed, while for ruling-in, a PTP $\geq 80 \%[76,83]$ is required.

As expected, the performance of imaging methods was clearly better than that of stress ECG. However, there appears to be also differences between them. A negative result in CCTA, which conveys a strong LR-, can exclude anatomically defined CAD in nearly all patients independently of their pre-test probability. The performance was clearly poorer when FFR was considered the reference standard as CCTA could only exclude functionally significant CAD at a PTP $\leq 57 \%[40,72]$. Correspondingly, the rule-in power, that was 
moderate to good when considering ICA as reference, also clearly deteriorated when FFR was used as reference standard.

The functional imaging techniques (PET, CMR, SPECT), which had only moderate power in identifying anatomically significant CAD, performed much better when FFR was used as reference standard. This is in agreement with previous notions and a recently published meta-analysis $(9,13)$. PET and stress CMR demonstrated the best diagnostic performance and offered reasonable range of pre-test probabilities where they could simultaneously rule-out or rule-in functionally significant CAD as shown in Figure 4. However, the comparison between functional imaging techniques must be done cautiously as not enough data was available for stress echocardiography and SPECT studies were older. Furthermore, in more recent studies, referral bias to reference technique is a common phenomenon with established techniques, which typically leads to underestimation of the test specificity. Also, the recent technical advances in were not accounted for as the data was heavily weighted by older studies. Therefore, the previously established tests may underperform in the present analysis.

We also assessed the performance of ICA itself in detecting functionally significant CAD even though it does not classify as a non-invasive test. ICA demonstrated the poorest ruling-out performance of all analyzed techniques when the reference standard was FFR as a PTP $\leq 27 \%[24,31]$ was needed to rule-out functional CAD. Consistently, the PTP range to rule-in functionally significant CAD was rather modest $(\geq 71 \%[59,81])$ and only slightly superior to CCTA $(\geq 75 \%[67,83])$. This behavior fits well with the current recommendation that ICA should be used primarily in patients with high PTP.

Although a pooled evaluation of non-invasive imaging techniques for diagnosing functionally significant CAD has been performed recently, (14) the present study expands the evidence by also considering stress ECG performance, evaluating the competence of ICA 
alone in determining functionally significant $\mathrm{CAD}$, conveying the practical ranges of application for the involved diagnostic techniques and parsing the determination of CAD both against anatomical and functional standards. This is timely and relevant considering that anatomical definition of CAD is still widely used in the daily clinical scenario in many healthcare centers around the world, while at the same time acknowledging that FFR indeed represents the currently most adequate reference standard.

\section{Clinical implications}

Our clinical conclusions partly differ from those in the current clinical guidelines. For example, in ESC guidelines (4) stress ECG is recommended in patients with lower intermediate PTP (15-65\%) of CAD. Our analysis argues against this statement as the practical utility of stress ECG in detecting CAD appears very limited (Figure 4A and e-Figure 2A). However, exercise testing also provides complementary information beyond ECG changes, such as exercise capacity, arrhythmias, hemodynamic response, and symptoms during exercise, which are considered clinically useful. These, however, could not be taken into account in the present analysis.

CCTA has rapidly gained popularity mainly based on its high negative predictive value. This was confirmed in the present analysis by the low LR-, which suggests that a negative result can reliably rule-out anatomic CAD virtually at any level of intermediate pretest probability (Figures 4A and e-Figure 2A). However, with a high probability of CAD, exclusion of disease is clinically less beneficial because, statistically, most patients will have the disease, and in order to rule-out CAD in one patient, a considerably large number of patients must be investigated. Additionally, the rule-out power decreased when considering FFR as reference. A known limitation of CCTA is low specificity, especially in identifying 
functionally significant CAD (53\%), and this links to our finding that a PTP $\geq 75 \%$ is required to rule it in (Figure 4B).

Not surprisingly, non-invasive imaging methods that characterize the functional consequences of CAD (rather than the coronary atherosclerotic lesions themselves) perform better when FFR is used as a reference standard and outperform CCTA (Figure 4A vs. 4B). Clearly, every technique has a particular diagnostic performance profile. The techniques focus on different levels of the ischemic cascade including wall motion abnormalities (echocardiography and stress CMR), relative perfusion abnormalities (stress CMR and SPECT), and changes in physiological absolute regional myocardial perfusion (PET).

Out of the functional imaging tests, PET and stress CMR demonstrated good performance with optimal application ranges (for both ruling-in and ruling-out disease) for anatomic and functional CAD. Stress echocardiography and SPECT perfusion imaging performance numbers appeared moderate but direct comparison to other methods must be done cautiously, for the reasons explained above. In addition, as shown in e-Figure 2, the clinical impact of these differences in the utility of the various functional tests is modest although detectable. It is also important to remember that accessibility, simplicity, expertise, personnel, and costs are still important determinants for choosing a given test, and unfortunately, these variables could not be included in this analysis.

Finally, the 2016 update of the stable chest pain guideline, the National Institute for Health and Care Excellence (NICE)(15) has chosen not to include the assessment of PTP and rather recommended CCTA as the first-line diagnostic test and ischemia testing as second step in those with suspected anatomically-relevant CAD. Our analysis does not argue against this approach but we would like to underline that such rationale will depend on the actual prevalence of CAD in the population. The PTP tables currently included in the guidelines are based on reasonably old data while the prevalence of CAD is continuously decreasing. With 
low prevalence of CAD the primary first task of imaging may be the accurate exclusion of anatomic $\mathrm{CAD}$, for which $\mathrm{CCTA}$ has demonstrated a strong role. The proposed sequential utilization of functional imaging tests may indeed be relevant but it must be kept in mind that the evidence is still limited although prognostic utility and overall safety appears to be excellent.(16)

\section{Limitations}

The performance of a given test in different publications varies due to numerous reasons such as population selection and referral bias. Age, gender or participants with history of MI may effect on the estimates of diagnostic accuracy but analyses of these characteristics on a group level may lead to spurious results due to the risk of ecological fallacy bias. We did not have access to individual patient level data or subgroup data that are needed to validly analyze these characteristics. Another potentially important source of variation or bias is study selection based on prior test results or known CAD. Although we excluded case-control studies, we do not know whether study selection was restricted to participants with specific prior test results. The inconsistency between studies lowers the confidence in the summary estimates and future studies should aim to dissect sources of bias and variation.

Furthermore, the present study considers visual analysis alone for the determination of significant CAD through ICA. Advances in ICA evaluation, such as QCA and the implementation of IVUS and OCT(17), could improve identification of hemodynamicallysignificant lesions. However, clinical practice in many centers currently relies on direct visual ICA evaluation and, therefore, our results on technique performances are likely to be widely applicable. The cutoff of $50 \%$ in ICA was used as this was available in all studies. In addition to known pitfalls of ICA, FFR is not without limitation as it is highly dependent on achieving hyperemia through maximal decrease in microvascular resistances. 
As the data was available only at the study-level in several reports, we cannot evaluate how the different techniques can assess the extent and severity of the disease, which are important factors in guiding therapies. As there are limited data on direct comparisons between modalities, differences could not be comprehensively tested.

With regard to analyses using FFR as the reference standard, the low number of identified studies did not allow analyzing all modalities. In addition, our summary estimates were vastly derived from single test accuracy studies, providing indirect evidence to compare test modalities. Due to the very low number of comparative studies identified, no consistency check could be performed between direct and indirect summary estimates. Therefore, small differences between techniques and summary estimates should be interpreted cautiously and considered as directional only. CCTA derived FFR has been investigated recently but this method is not yet well standardized and we decided not to include this method in the current analysis. It is also possible that the best diagnostic performance could be achieved when the tests are applied sequentially.(16) The relevance of complementary features in different techniques warrants further investigation. The supplemental technique selection guide (eFigure 2) was based on the PTP values published in 2013 ESC guidelines and is naturally susceptible to change when updated PTP values are available.

\section{CONCLUSIONS}

The various diagnostic modalities have different optimal performance ranges for the detection of anatomically and functionally significant CAD. Stress ECG appears to have limited diagnostic value at any level of pre-test probability. Imaging methods perform generally better but also have different strengths and weaknesses. CCTA performs best against anatomical reference standard and functional tests perform better than CCTA or ICA for functionally significant CAD. 
The selection of a diagnostic technique for any given patient to rule-in or rule-out CAD should be based on the optimal PTP range for each test. Using LRs we were able to create individual pre-test ranges for each test to rule-in and/or rule-out anatomic or functional $\mathrm{CAD}$, and these can be used in aiding in the selection of a diagnostic technique for a given patient. 


\section{FUNDING}

This work was supported by The Academy of Finland Centre of Excellence on Cardiovascular and Metabolic Disease, Helsinki, Finland and the Finnish Foundation for Cardiovascular Research.

Study supervision: Knuuti

\section{ACKNOWLEDGEMENTS}

Knuuti, Ballo, Rutjes and Juarez-Orozco had full access to all of the data in the study and take responsibility for the integrity of the data and the accuracy of the data analysis. Concept and design: Knuuti, Wijns, Bax. Acquisition, analysis, or interpretation of data: Knuuti, Ballo, Juarez-Orozco, Saraste, Kolh, Rutjes, Jüni, Windecker, Bax, Wijns. Drafting of the manuscript: Knuuti, Juarez-Orozco. Critical revision of the manuscript for important intellectual content: Knuuti, Ballo, Juarez Orozco, Saraste, Kolh, Rutjes, Jüni, Windecker, Bax, Wijns. Statistical analyses: Rutjes

\section{CONFLICT OF INTEREST STATEMENT}

Dr. Ballo, Dr. Juarez-Orozco, and Dr. Rutjes have no competing interests. Dr Knuuti has personal fees from Astra Zeneca outside the submitted work. Dr. Saraste reportspersonal fees from Astra Zeneca, Abbott, Bayer, Actelion, GE, and Novartis, outside the submitted work. Dr. Kolh reports personal fees from Astra Zeneca, B-Braun, Ferrer, outside the submitted work. Dr. Jüni reports grants from Astra Zeneca, grants from Biotronik, grants from Biosensors International, grants from Eli Lilly, grants from The Medicines Company, nonfinancial support from Astra Zeneca, Biotronik, Biosensors, St Jude Medical, and The Medicines Company, during the conduct of the study. Dr. Windecker reports grants from Biotronik, Boston Scientific, Bracco Pharmaceutical, Edwards Lifesciences, Medtronic, Terumo Inc, and St Jude Medical, outside the submitted work. Dr. Bax reports grants from Biotronik, Medtronic, Boston Scientific, and Edwards Lifesciences, outside the submitted work. Dr. Wijns reports grants from St Jude now Abbott, Terumo, MicroPort, personal fees from Biotronik, MicroPort, outside the submitted work; and Co-founder of Argonauts Partners; former non-executive Board member of Genae and Cardio3BioSciences (now Celyad). 


\section{REFERENCES}

1. Tonino PAL, Fearon WF, De Bruyne B, Oldroyd KG, Leesar MA, Ver Lee PN, Maccarthy PA, Van’t Veer M, Pijls NHJ. Angiographic versus functional severity of coronary artery stenoses in the FAME study fractional flow reserve versus angiography in multivessel evaluation. J Am Coll Cardiol. 2010 Jun 22;55(25):2816-21.

2. Fihn SD, Blankenship JC, Alexander KP, Bittl JA, Byrne JG, Fletcher BJ, Fonarow GC, Lange RA, Levine GN, Maddox TM, Naidu SS, Ohman EM, Smith PK. 2014 ACC/AHA/AATS/PCNA/SCAI/STS focused update of the guideline for the diagnosis and management of patients with stable ischemic heart disease: a report of the American College of Cardiology/American Heart Association Task Force on Practice Guidelines, a. J Am Coll Cardiol. 2014 Nov 4;64(18):1929-49.

3. Pothineni N V., Shah NN, Rochlani Y, Nairooz R, Raina S, Leesar MA, Uretsky BF, Hakeem A. U.S. Trends in Inpatient Utilization of Fractional Flow Reserve and Percutaneous Coronary Intervention. J Am Coll Cardiol. 2016 Feb 16;67(6):732-3.

4. Task Force Members, Montalescot G, Sechtem U, Achenbach S, Andreotti F, Arden C, Budaj A, Bugiardini R, Crea F, Cuisset T, Di Mario C, Ferreira JR, Gersh BJ, Gitt AK, Hulot J-S, Marx N, Opie LH, Pfisterer M, Prescott E, Ruschitzka F, Sabaté M, Senior R, Taggart DP, van der Wall EE, Vrints CJM, ESC Committee for Practice Guidelines, Zamorano JL, Achenbach S, Baumgartner H, Bax JJ, Bueno H, Dean V, Deaton C, Erol C, Fagard R, Ferrari R, Hasdai D, Hoes AW, Kirchhof P, Knuuti J, Kolh P, Lancellotti P, Linhart A, Nihoyannopoulos P, Piepoli MF, Ponikowski P, Sirnes PA, Tamargo JL, Tendera M, Torbicki A, Wijns W, Windecker S, Document Reviewers, Knuuti J, Valgimigli M, Bueno H, Claeys MJ, Donner-Banzhoff N, Erol C, Frank H, Funck-Brentano C, Gaemperli O, Gonzalez-Juanatey JR, Hamilos M, Hasdai D, Husted S, James SK, Kervinen K, Kolh P, Kristensen SD, Lancellotti P, Maggioni A Pietro, Piepoli MF, Pries AR, Romeo F, Rydén L, Simoons ML, Sirnes PA, Steg PG, Timmis A, Wijns W, Windecker S, Yildirir A, Zamorano JL. 2013 ESC guidelines on the management of stable coronary artery disease: the Task Force on the management of stable coronary artery disease of the European Society of Cardiology. Eur Heart J. 2013 Oct;34(38):2949-3003. 
5. Diamond GA, Kaul S. Gone fishing!: on the "real-world" accuracy of computed tomographic coronary angiography: Comment on the "Ontario multidetector computed tomographic coronary angiography study”. Arch Intern Med. 2011 Jun 13;171(11):1029-31.

6. Miller TD, Roger VL, Hodge DO, Gibbons RJ. A simple clinical score accurately predicts outcome in a community-based population undergoing stress testing. Am J Med. 2005 Aug;118(8):866-72.

7. Nakazato R, Berman DS, Alexanderson E, Slomka P. Myocardial perfusion imaging with PET. Imaging Med. 2013 Feb 1;5(1):35-46.

8. Steurer J, Fischer JE, Bachmann LM, Koller M, ter Riet G. Communicating accuracy of tests to general practitioners: a controlled study. BMJ. 2002 Apr 6;324(7341):824-6.

9. Danad I, Szymonifka J, Twisk JWR, Norgaard BL, Zarins CK, Knaapen P, Min JK. Diagnostic performance of cardiac imaging methods to diagnose ischaemia-causing coronary artery disease when directly compared with fractional flow reserve as a reference standard: a metaanalysis. Eur Heart J. 2017 Apr 1;38(13):991-8.

10. Moher D, Liberati A, Tetzlaff J, Altman DG, PRISMA Group. Preferred reporting items for systematic reviews and meta-analyses: the PRISMA statement. PLoS Med. 2009 Jul 21;6(7):e1000097.

11. Stroup DF, Berlin JA, Morton SC, Olkin I, Williamson GD, Rennie D, Moher D, Becker BJ, Sipe TA, Thacker SB. Meta-analysis of observational studies in epidemiology: a proposal for reporting. Meta-analysis Of Observational Studies in Epidemiology (MOOSE) group. JAMA. 2000 Apr 19;283(15):2008-12.

12. Reitsma JB, Glas AS, Rutjes AWS, Scholten RJPM, Bossuyt PM, Zwinderman AH. Bivariate analysis of sensitivity and specificity produces informative summary measures in diagnostic reviews. J Clin Epidemiol. 2005;58(10):982-90.

13. Carlsson M. The impacts on healthcare when coronary angiography as the reference method for diagnostic accuracy of coronary artery disease is replaced by fractional flow reserve! Eur Heart J. 2017 Apr 1;38(13):999-1001.

14. Takx RAP, Blomberg BA, Aidi HE, Habets J, de Jong PA, Nagel E, Hoffmann U, Leiner T. 
Diagnostic Accuracy of Stress Myocardial Perfusion Imaging Compared to Invasive Coronary Angiography With Fractional Flow Reserve Meta-Analysis. Circ Cardiovasc Imaging. 2015;8(1):e002666-e02666.

15. National Institute for Health and Clinical Excellence. Chest pain of recent onset: assessment and diagnosis of recent onset chest pain or discomfort of suspected cardiac origin. Clinical guideline CG95. 2010.

16. Maaniitty T, Stenström I, Bax JJ, Uusitalo V, Ukkonen H, Kajander S, Mäki M, Saraste A, Knuuti J. Prognostic Value of Coronary CT Angiography With Selective PET Perfusion Imaging in Coronary Artery Disease. JACC Cardiovasc Imaging. 2017 May 15;

17. Pyxaras SA, Tu S, Barbato E, Barbati G, Di Serafino L, De Vroey F, Toth G, Mangiacapra F, Sinagra G, De Bruyne B, Reiber JHC, Wijns W. Quantitative angiography and optical coherence tomography for the functional assessment of nonobstructive coronary stenoses: comparison with fractional flow reserve. Am Heart J. 2013;166(6):1010-1018.e1. 


\section{FIGURE LEGENDS}

Figure 1. Study search and selection flow chart.

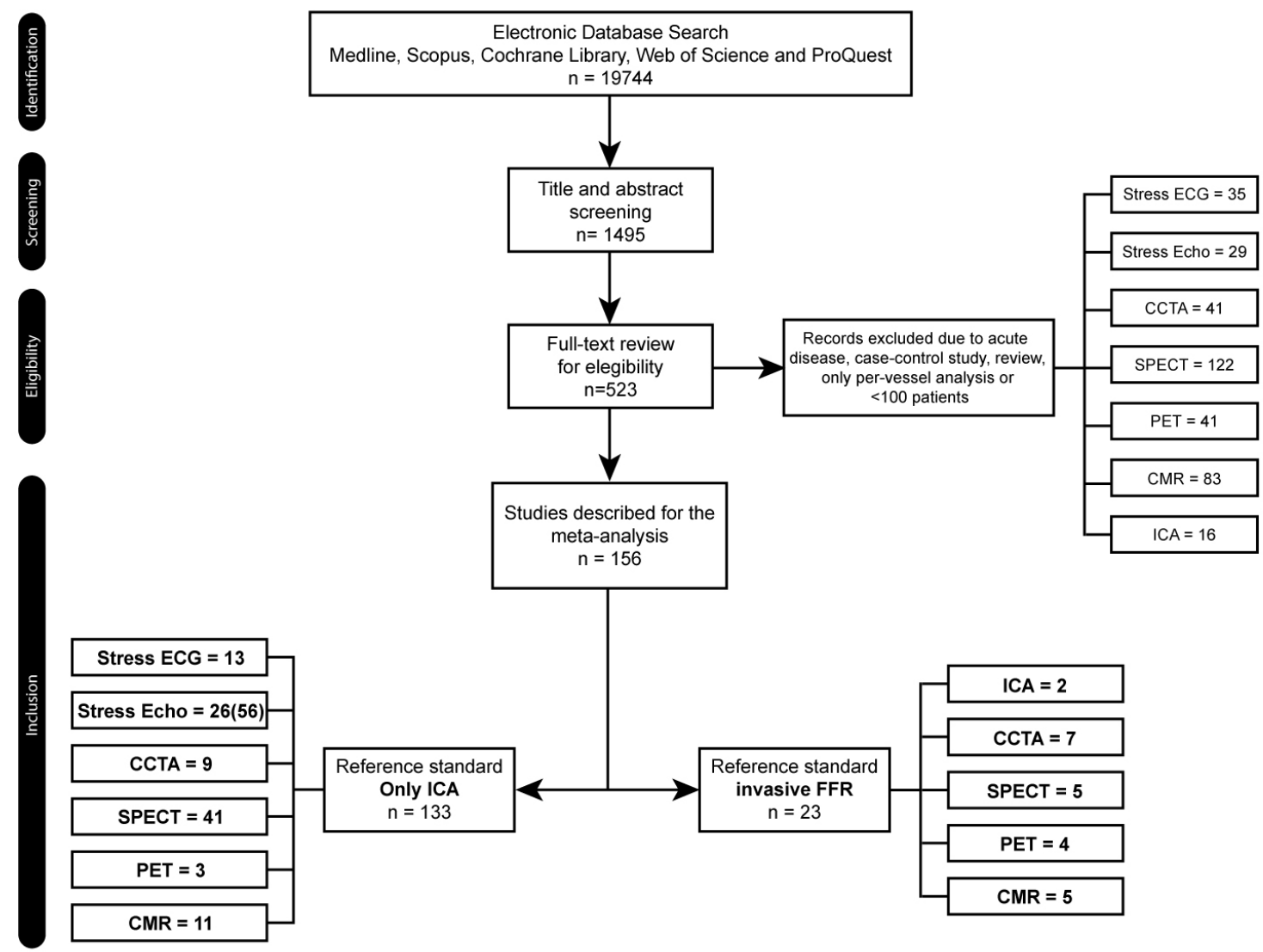

Figure 2. QUADAS assessment summary by type of reference standard for significant CAD.

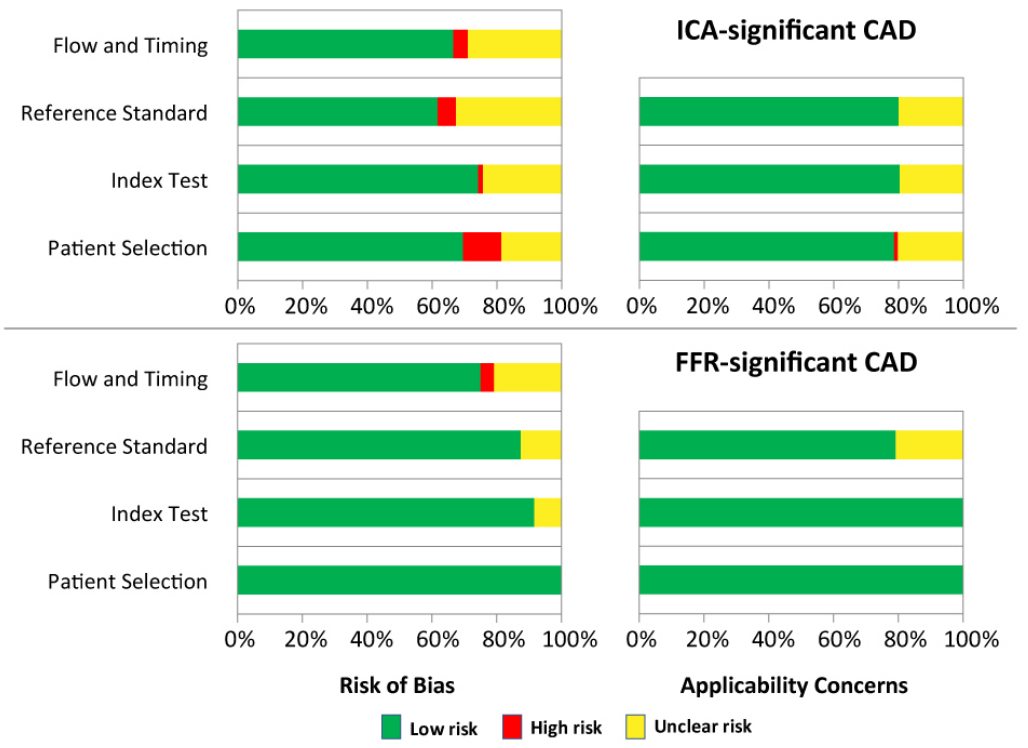


Figure 3. Fagan Nomogram. A hypothetical patient with a calculated pre-test probability of CAD of 56\% (left-sided scales in panels A and B) undergoes: a stress ECG, CCTA or PET when anatomically significant CAD is used as the reference standard (panel A), and SPECT, CCTA or PET when functionally significant CAD is used as the reference (panel $\mathbf{B}$ ). In the middle scales, LR+ and LR- are identified and straight lines are drawn between the left and middle scales, and extrapolated to reach the right-sided scales. In the right-sided scales of both panels (A and B), the post-test probability of a positive and negative test result can be read. The grey bars represents the range of post-test probability in which CAD cannot confidently ruled-in or ruled-out (post-test probability $15-85 \%$ ). Notice that in panel A, stress ECG cannot rule-in or -out but the other two imaging tests can, while in panel $\mathbf{B}$, SPECT cannot rule-in or-out, CCTA can only rule-out, and PET can do both.
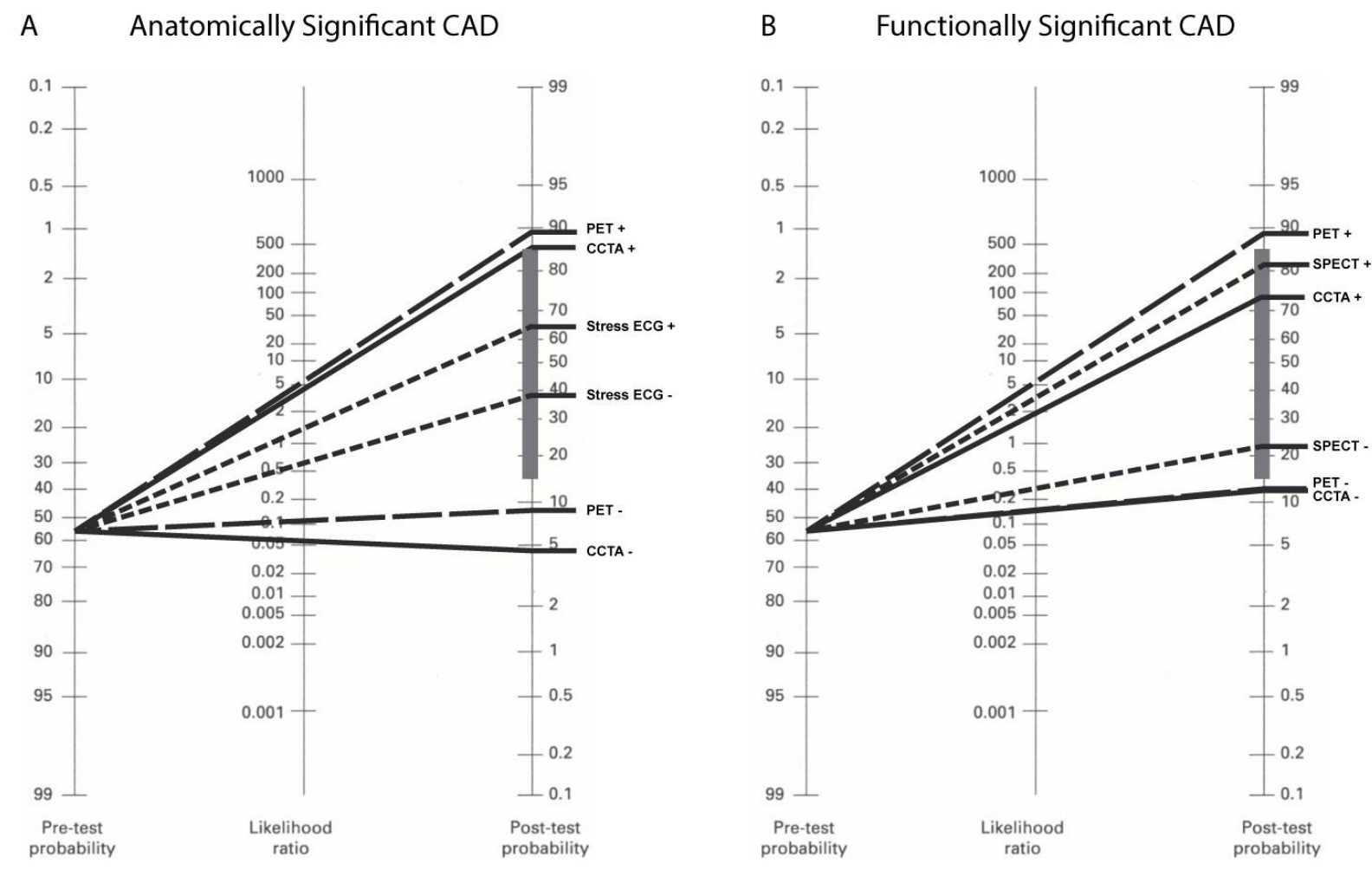
Figure 4. Ranges of clinical pre-test probability in which each single positive test will confidently rule-in (in ORANGE) the presence of significant CAD or, conversely a negative test will confidently rule-out (in GREEN) based on the LR values of the test. Panel A shows these ranges when the reference standard is visually significant stenosis in ICA, while Panel B shows the ranges when abnormal FFR is the reference standard. The crosshairs mark the mean value and the gradient-colored areas contain their $95 \%$ CIs. The results are based on the criteria that disease is confidently ruled-out when the post-test probability is $<15 \%$ and ruledin when it is $>85 \%$. The numeric values can be consulted in Supplementary e-Table 4.

A

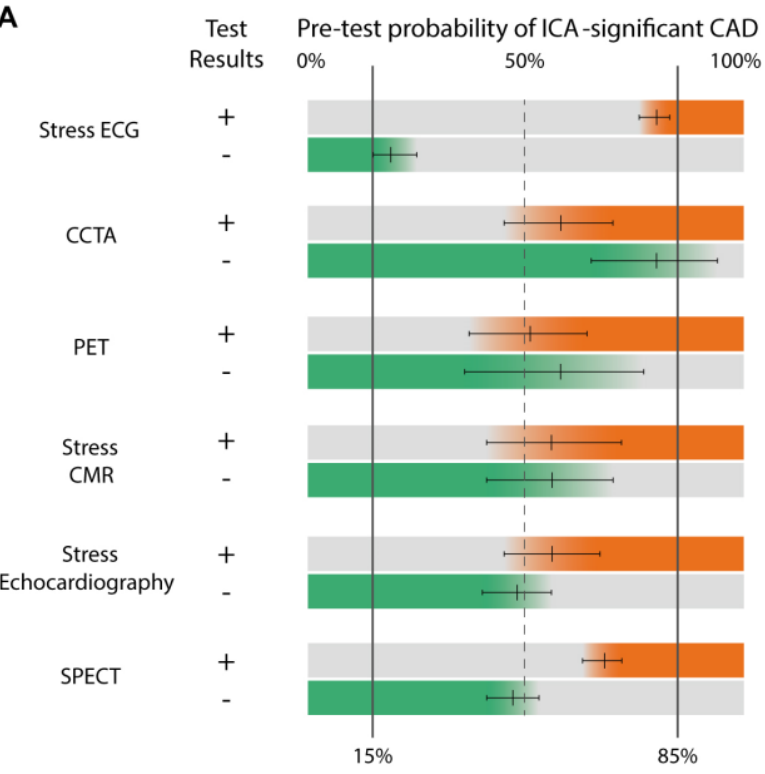

B

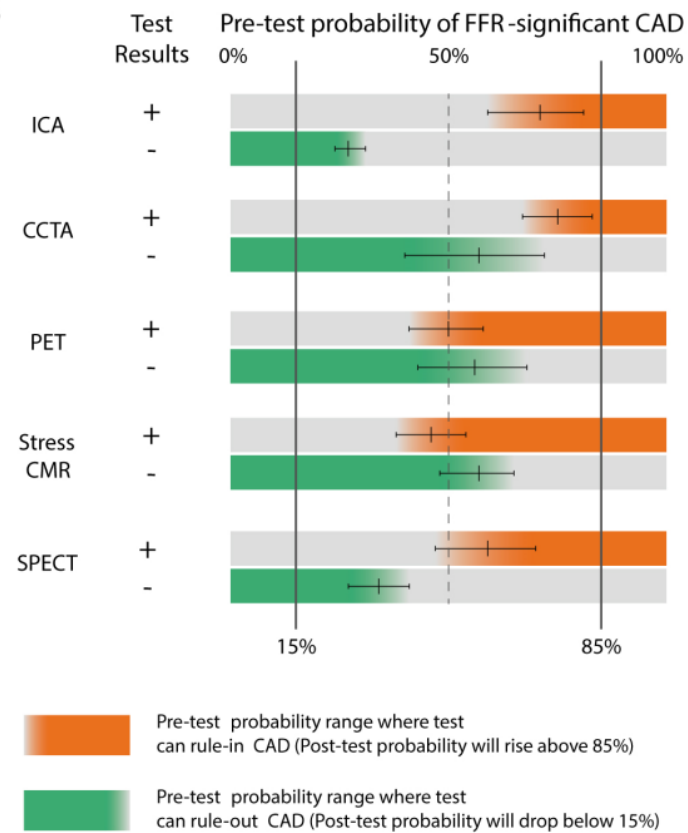




\section{TABLES}

Table 1. The performance of different tests for anatomically (left panel) and functionally significant CAD (right panel). Note: ICA itself was used as a reference standard for the left panel estimates but was included as a technique when FFR was used as the reference. Not every test had enough data using FFR as reference.

Anatomically Significant CAD

\begin{tabular}{ccccc|}
\hline Test & $\begin{array}{c}\text { Sensitivity } \\
{[\mathbf{9 5 \%} \mathbf{C I}]}\end{array}$ & $\begin{array}{c}\text { Specificity } \\
{[\mathbf{9 5 \%} \mathbf{C I}]}\end{array}$ & $\begin{array}{c}+\mathbf{L R} \\
{[\mathbf{9 5 \%} \mathbf{C I}]}\end{array}$ & $\begin{array}{c}\mathbf{- L R} \\
{[\mathbf{9 5 \%} \mathbf{C I}]}\end{array}$ \\
\hline & & & & \\
& & & & \\
& & & & \\
Stress & $58 \%$ & $62 \%$ & 1.53 & 0.68 \\
ECG & {$[46,69]$} & {$[54,69]$} & {$[1.21,1.94]$} & {$[0.49,0.93]$} \\
& & & & \\
Stress & $85 \%$ & $82 \%$ & 4.67 & 0.18 \\
Echo & {$[80,89]$} & {$[72,89]$} & {$[2.95,7.41]$} & {$[0.13,0.25]$}
\end{tabular}

\begin{tabular}{cccccc|ccccc} 
CCTA & $97 \%$ & $78 \%$ & 4.44 & 0.04 & CCTA & $93 \%$ & $53 \%$ & 1.97 & 0.13 \\
& {$[93,99]$} & {$[67,86]$} & {$[2.64,7.45]$} & {$[0.01,0.09]$} & & {$[89,96]$} & {$[37,68]$} & {$[1.28,3.03]$} & {$[0.06,0.25]$} \\
& & & & & & & & & & \\
\multirow{2}{*}{ SPECT } & $87 \%$ & $70 \%$ & 2.88 & 0.19 & SPECT & $73 \%$ & $83 \%$ & 4.21 & 0.33 \\
& {$[83,90]$} & {$[63,76]$} & {$[2.33,3.56]$} & {$[0.15,0.24]$} & & {$[62,82]$} & {$[71,90]$} & {$[2.62,6.76]$} & {$[0.24,0.46]$}
\end{tabular}

\begin{tabular}{ccccc|ccccc} 
PET & $90 \%$ & $85 \%$ & 5.87 & 0.12 & PET & $89 \%$ & $85 \%$ & 6.04 & 0.13 \\
& {$[78,96]$} & {$[78,90]$} & {$[3.40$,} & {$[0.05,0.29]$} & & {$[82,93]$} & {$[81,88]$} & {$[4.29,8.51]$} & {$[0.08,0.22]$} \\
& & & $10.15]$ & & & & & & \\
Stress & $90 \%$ & $80 \%$ & 4.54 & 0.13 & Stress & $89 \%$ & $87 \%$ & 7.10 & 0.13 \\
CMR & {$[83,94]$} & {$[69,88]$} & {$[2.37,8.72]$} & {$[0.07,0.24]$} & CMR & {$[85,92]$} & {$[83,91]$} & {$[5.07,9.95]$} & {$[0.09,0.18]$}
\end{tabular}

Abbreviations: CI, confidence intervals; CMR, stress cardiac magnetic resonance; CCTA, computed tomography; ECG,

electrocardiogram; ICA, invasive coronary angiography; LR, likelihood ratio; PET, positron emission tomography; SPECT, single photon emission computed tomography (Exercise stress SPECT with or without Dipyridamole or Adenosine); Stress Echo, exercise stress echocardiography 


\section{ONLINE SUPPLEMENTARY MATERIAL}

\section{The performance of non-invasive tests to rule-in and rule-out significant coronary artery stenosis in patients with stable angina: A meta-analysis focused on post-test disease likelihood}

Table S1. MOOSE Checklist.

\begin{tabular}{|c|c|c|}
\hline Items & Recommendation & Described in element or page \\
\hline \multicolumn{3}{|c|}{ Reporting of background should include } \\
\hline 1 & Problem definition & 6 \\
\hline 2 & Hypothesis statement & 6 \\
\hline 3 & Description of study outcome(s) & 8 \\
\hline 4 & Type of exposure or intervention used (non-invasive techniques) & $6-7$ \\
\hline 5 & Type of study designs used & 7 \\
\hline 6 & Study population & 7 \\
\hline \multicolumn{3}{|c|}{ Reporting of search strategy should include } \\
\hline 7 & Qualifications of searchers (eg, librarians and investigators) & $7-8$ \\
\hline 8 & Search strategy, including time period included in the synthesis and key words & 7 \\
\hline 9 & Effort to include all available studies, including contact with authors & 8 \\
\hline 10 & Databases and registries searched & 7 \\
\hline 11 & $\begin{array}{l}\text { Search software used, name and version, including special features used (eg, } \\
\text { explosion) }\end{array}$ & 7 \\
\hline 12 & Use of hand searching (eg, reference lists of obtained articles) & 7 \\
\hline 13 & List of citations located and those excluded, including justification & Fig 1 and E-table 2 \\
\hline 14 & Method of addressing articles published in languages other than English (na) & 7 \\
\hline 15 & Method of handling abstracts and unpublished studies & 7 \\
\hline 16 & Description of any contact with authors & $7-8$ \\
\hline \multicolumn{3}{|c|}{ Reporting of methods should include } \\
\hline 17 & $\begin{array}{l}\text { Description of relevance or appropriateness of studies assembled for assessing the } \\
\text { hypothesis to be tested }\end{array}$ & $7-8$ \\
\hline 18 & $\begin{array}{l}\text { Rationale for the selection and coding of data (eg, sound clinical principles or } \\
\text { convenience) }\end{array}$ & 9 \\
\hline 19 & $\begin{array}{l}\text { Documentation of how data were classified and coded (eg, multiple raters, blinding } \\
\text { and interrater reliability) }\end{array}$ & 8 \\
\hline 20 & $\begin{array}{l}\text { Assessment of confounding (eg, comparability of cases and controls in studies where } \\
\text { appropriate) }\end{array}$ & $7-8$ \\
\hline 21 & $\begin{array}{l}\text { Assessment of study quality, including blinding of quality assessors, stratification or } \\
\text { regression on possible predictors of study results }\end{array}$ & 7, Fig 2 \\
\hline 22 & Assessment of heterogeneity & $8-9,10$ \\
\hline 23 & $\begin{array}{l}\text { Description of statistical methods (eg, complete description of fixed or random effects } \\
\text { models, justification of whether the chosen models account for predictors of study } \\
\text { results, dose-response models, or cumulative meta-analysis) in sufficient detail to be } \\
\text { replicated }\end{array}$ & $8-9$ \\
\hline 24 & Provision of appropriate tables and graphics & Fig 1-5, E-table 1,3 \\
\hline \multicolumn{3}{|c|}{ Reporting of results should include } \\
\hline 25 & Graphic summarizing individual study estimates and overall estimate & Fig 4, Table 1 \\
\hline
\end{tabular}




\begin{tabular}{|c|c|c|}
\hline 26 & Table giving descriptive information for each study included & e-Table 2 \\
\hline 27 & Results of sensitivity testing (eg, subgroup analysis) & 11 \\
\hline 28 & Indication of statistical uncertainty of findings & 11,16 \\
\hline \multicolumn{3}{|c|}{ Reporting of discussion should include } \\
\hline 29 & Quantitative assessment of bias (eg, publication bias) & NA \\
\hline 30 & Justification for exclusion (eg, exclusion of non-English language citations) & Fig 1 \\
\hline 31 & Assessment of quality of included studies & Fig 2 and e-Fig 1 \\
\hline \multicolumn{3}{|c|}{ Reporting of conclusions should include } \\
\hline 32 & Consideration of alternative explanations for observed results & $16-17$ \\
\hline 33 & $\begin{array}{l}\text { Generalization of the conclusions (ie, appropriate for the data presented and within the } \\
\text { domain of the literature review) }\end{array}$ & 19, Fig 5 \\
\hline 34 & Guidelines for future research & 18 \\
\hline 35 & Disclosure of funding source & 20 \\
\hline
\end{tabular}

Table S2. Electronic search terms

\begin{tabular}{ll}
\hline Search string & ("Electrocardiography"[Mesh] OR stress ECG OR stress electrocardiography) OR \\
& ("Echocardiography, Stress"[Mesh] OR stress echocardio*) OR ("Computed Tomography \\
& Angiography"[Mesh] OR coronary computed tomography angiography OR CCTA OR \\
& coronary angiotomography OR MDCT) OR ("Tomography, Emission-Computed, Single- \\
& Photon"[Mesh] OR SPECT OR SPET) OR ("Positron-Emission Tomography"[Mesh] OR \\
& PET) OR ("Magnetic Resonance Imaging"[Mesh] OR cardiac magnetic resonance OR \\
& CMR) OR ("Coronary Angiography"[Mesh] OR invasive coronary angiography OR ICA) \\
& OR ("Fractional Flow Reserve, Myocardial"[Mesh] OR FFR)) AND (("Coronary Artery \\
& Disease"[Mesh] OR stable coronary artery disease OR stable CAD OR stable angina)) \\
& AND ((diagnosis OR performance)) \\
\hline Filter & Human Studies \\
\hline
\end{tabular}


Table S3. Characteristics of included studies on diagnosis of angiographically and functionally significant CAD. The full reference list in included after the table.

\begin{tabular}{|c|c|c|c|c|c|c|c|c|c|c|}
\hline Study & Year & Reference & $\begin{array}{c}\text { No. of } \\
\text { patients }\end{array}$ & Mean Age & Women (\%) & $\begin{array}{c}\text { Prior MI } \\
(\%)\end{array}$ & Sensitivity (\%) & Specificity (\%) & $\begin{array}{c}\text { Prevalence of } \\
\text { CAD }(\%)\end{array}$ & Technique \\
\hline Amanuallah $^{1}$ & 1997 & ICA & 222 & 71 & 46 & 0 & 92.9 & 72.6 & 76.7 & SPECT Vasodilator \\
\hline Anthopoulos ${ }^{2}$ & 1996 & ICA & 120 & 75 & 40 & 40 & 86.5 & 83.9 & 74.2 & Echo Dobutamine \\
\hline Bateman $^{3}$ & 2006 & ICA & 112 & 67 & 54 & 25 & 87.1 & 92.9 & 62.5 & PET \\
\hline Beleslin $^{4}$ & 1994 & ICA & 136 & 50 & 14.7 & 56.6 & 87.4 & 82.4 & 87.5 & Echo Exercise \\
\hline Beleslin $^{4}$ & 1994 & ICA & 136 & 50 & 14.7 & 56.6 & 74 & 94.1 & 87.5 & Echo Vasodilator \\
\hline Beleslin ${ }^{4}$ & 1994 & ICA & 136 & 50 & 14.7 & 56.6 & 82.4 & 76.5 & 87.5 & Echo Dobutamine \\
\hline Berman $^{5}$ & 2006 & ICA & 785 & N/A & N/A & 0 & 90.6 & 55.5 & 70.7 & SPECT Vasodilator \\
\hline Berman $^{5}$ & 2006 & ICA & 290 & N/A & N/A & 0 & 82.7 & 86.2 & 77.6 & SPECT Vasodilator \\
\hline Berman $^{5}$ & 2006 & ICA & 365 & NA & NA & 0 & 91.3 & 55.6 & 75.3 & SPECT Exercise \\
\hline Bernhardt $^{6}$ & 2009 & ICA & 823 & 64 & 24 & N/A & 87.5 & 82.6 & 38 & Stress CMR \\
\hline Bettencourt $^{7}$ & 2013 & FFR & 101 & 62 & 23 & 0 & 100 & 61.4 & 43.6 & CCTA \\
\hline Bettencourt $^{7}$ & 2013 & FFR & 101 & 62 & 34 & 0 & 88.6 & 87.7 & 43.6 & Stress CMR \\
\hline Beygui $^{8}$ & 2000 & ICA & 179 & 61 & 16.2 & 4.5 & 50.8 & 62.3 & 36.3 & Stress ECG \\
\hline Bokhari $^{9}$ & 2008 & ICA & 218 & 56 & 31 & 0 & 81.1 & 78.7 & 65.6 & SPECT Exercise \\
\hline Budoff $^{10}$ & 2008 & ICA & 227 & 57 & 41 & 0 & 94.5 & 82.6 & 24.2 & CCTA \\
\hline Celutkine $^{11}$ & 2012 & ICA & 151 & 62 & 41.1 & 0 & 83 & 92.9 & 35.1 & Echo Dobutamine \\
\hline Chae $^{12}$ & 1993 & ICA & 243 & 62 & 100 & 42 & 71.2 & 65 & 67.1 & SPECT Exercise \\
\hline Chae $^{12}$ & 1993 & ICA & 243 & 65 & 100 & 42 & 25.1 & 38.2 & 72 & Stress ECG \\
\hline Chen ${ }^{13}$ & 2013 & ICA & 151 & 65 & 40 & 0 & 92.3 & 95.7 & 35.9 & Stress CMR \\
\hline Christian $^{14}$ & 1992 & ICA & 688 & 63 & 23 & 42 & 91.8 & 39.4 & 81.3 & SPECT Exercise \\
\hline Crouse $^{15}$ & 1991 & ICA & 228 & 62 & 32.9 & 0 & 97.1 & 64.2 & 76.8 & Echo Exercise \\
\hline Danad $^{16}$ & 2014 & FFR & 281 & 61 & 32 & 0 & 89.3 & 84 & 39.9 & PET \\
\hline Danad $^{17}$ & 2013 & FFR & 120 & 58 & 49 & 0 & 75 & 83.1 & 40.8 & PET \\
\hline Daou $^{18}$ & 2002 & ICA & 338 & 56 & 17 & 60 & 63 & 76.7 & 78.4 & SPECT Exercise \\
\hline Daou ${ }^{18}$ & 2002 & ICA & 338 & 59 & 8.3 & 59.8 & 46.9 & 63.8 & 76.3 & Stress ECG \\
\hline DeFACTO study ${ }^{19}$ & 2012 & FFR & 252 & 62.9 & 29.4 & 6 & 83.9 & 41.7 & 54.4 & CCTA \\
\hline DISCOVER-FLOW ${ }^{20}$ & 2011 & FFR & 103 & 62.7 & 28 & 17 & 94.8 & 24.4 & 56.3 & CCTA \\
\hline
\end{tabular}




\begin{tabular}{|c|c|c|c|c|c|c|c|c|c|c|}
\hline Dolan $^{21}$ & 2001 & ICA & 112 & 61 & 45 & 22 & 71.4 & 81 & 81.3 & Echo Dobutamine \\
\hline Dondi $^{22}$ & 2004 & ICA & 130 & 63.2 & 40 & 0 & 96.3 & 72.7 & 83.1 & SPECT Exercise \\
\hline Doyle $^{23}$ & 2003 & ICA & 184 & 59 & 100 & N/A & 61.5 & 82.3 & 14.1 & SPECT Vasodilator \\
\hline Ebersberger $^{24}$ & 2013 & FFR & 116 & 63 & 39 & 0 & 85 & 86.8 & 34.5 & Stress CMR \\
\hline Elhendy ${ }^{25}$ & 1996 & ICA & 133 & 60 & 23.5 & N/A & 78.4 & 86.4 & 83.5 & Echo Dobutamine \\
\hline Elhendy ${ }^{26}$ & 1998 & ICA & 290 & 58 & 30.3 & N/A & 72.2 & 85.5 & 76.2 & Echo Dobutamine \\
\hline Elhendy ${ }^{27}$ & 1998 & ICA & 295 & N/A & N/A & N/A & 75 & 86.8 & 77 & Echo Dobutamine \\
\hline Emmett $^{28}$ & 2002 & ICA & 100 & 60 & 23 & 0 & 88.6 & 63.3 & 70 & SPECT Exercise \\
\hline EVINCI-study ${ }^{29}$ & 2015 & ICA & 293 & 60.9 & 39 & 0 & 73 & 66.8 & 34 & SPECT Vasodilator \\
\hline EVINCI-study ${ }^{29}$ & 2015 & ICA & 475 & 60.9 & 39 & 0 & 90.7 & 91.9 & 29.4 & CCTA \\
\hline Ferrara $^{30}$ & 1991 & ICA & 109 & 62 & 37.7 & N/A & 78.9 & 99 & 82.6 & Echo Vasodilator \\
\hline Fragasso $^{31}$ & 1999 & ICA & 101 & 61 & 45.5 & 0 & 61.4 & 90.9 & 56.4 & Echo Vasodilator \\
\hline Fragasso $^{31}$ & 1999 & ICA & 101 & 61 & 45.5 & 0 & 87.7 & 79.6 & 56.4 & Echo Dobutamine \\
\hline Gallowitsch $^{32}$ & 1998 & ICA & 107 & 64 & 46 & 39.3 & 94.3 & 90.7 & 49.5 & SPECT Vasodilator \\
\hline Greenwood $^{33}$ & 2012 & ICA & 752 & 65 & 37 & 0 & 86.5 & 83.4 & 39.4 & Stress CMR \\
\hline Geleijnse $^{34}$ & 1995 & ICA & 223 & 58 & 31.4 & 0 & 72 & 78.8 & 64.1 & Echo Dobutamine \\
\hline Gentile $^{35}$ & 2001 & ICA & 132 & 70 & 31 & 0 & 93.5 & 54.2 & 81.8 & SPECT Vasodilator \\
\hline Gentile $^{35}$ & 2001 & ICA & 132 & 70 & 31.8 & 0 & 85.2 & 58.3 & 81.8 & Stress ECG \\
\hline $\mathrm{Go}^{36}$ & 1990 & ICA & 202 & NA & NA & 47 & 93.4 & 78 & 75.3 & PET \\
\hline Gonzalez $^{37}$ & 2005 & ICA & 145 & 60 & 32 & 36 & 87.2 & 57.1 & 80.5 & SPECT Vasodilator \\
\hline Greenwood $^{33}$ & 2012 & ICA & 752 & 60 & 37 & 0 & 66.5 & 82.7 & 39.4 & SPECT Vasodilator \\
\hline Groothuis $^{38}$ & 2013 & ICA & 192 & 56 & 51 & 0 & 85.5 & 81.3 & 35.9 & Stress CMR \\
\hline Groutars $^{39}$ & 2003 & ICA & 123 & 63 & 27.6 & 52 & 96.9 & 59.3 & 78.1 & SPECT Exercise \\
\hline Gueret $^{40}$ & 2013 & ICA & 746 & 61 & 29 & 20 & 91 & 50 & 34.7 & CCTA \\
\hline Hamasaki $^{41}$ & 1996 & ICA & 125 & 64 & 24 & 0 & 83 & 65.4 & 37.6 & Stress ECG \\
\hline Hambye $^{42}$ & 2004 & ICA & 100 & 63 & 52 & 43 & 73.3 & 78.6 & 86 & SPECT Vasodilator \\
\hline Hanekom $^{43}$ & 2007 & ICA & 150 & 66 & 33 & 19 & 91 & 52.5 & 59.3 & Echo Dobutamine \\
\hline Hecht $^{44}$ & 1993 & ICA & 180 & 56 & 13.9 & N/A & 93.4 & 86.1 & 76.1 & Echo Exercise \\
\hline Hecht $^{45}$ & 1993 & ICA & 136 & 59 & 11 & N/A & 83 & 90.5 & 69.1 & Echo Exercise \\
\hline Hecht ${ }^{46}$ & 1990 & ICA & 116 & 58 & 19.8 & 42.2 & 51.5 & 64.6 & 58.6 & Stress ECG \\
\hline
\end{tabular}




\begin{tabular}{|c|c|c|c|c|c|c|c|c|c|c|}
\hline Hennessy $^{47}$ & 1997 & ICA & 317 & 60 & 27.8 & 42.2 & 85.4 & 60.5 & 86.4 & Echo Dobutamine \\
\hline Hennessy ${ }^{48}$ & 1998 & ICA & 218 & 62 & 100 & 47.7 & 49 & 85 & 90.8 & Echo Dobutamine \\
\hline Hida $^{49}$ & 2009 & ICA & 119 & 68 & 33 & 0 & 51.6 & 87.7 & 52.1 & SPECT Vasodilator \\
\hline $\mathrm{Ho}^{50}$ & 1997 & ICA & 223 & 58 & 19.3 & N/A & 93.8 & 78.7 & 72.7 & Echo Dobutamine \\
\hline Hoffmann ${ }^{51}$ & 1996 & ICA & 150 & 46 & 20.5 & 0 & 75.8 & 87.3 & 63.3 & Echo Dobutamine \\
\hline Hoffmann $^{52}$ & 1999 & ICA & 283 & 56 & 33.3 & 0 & 72.1 & 78 & 64.7 & Echo Dobutamine \\
\hline Hung ${ }^{53}$ & 2006 & ICA & 126 & 66 & 30 & 8.7 & 92.6 & 64.4 & 64.3 & SPECT Vasodilator \\
\hline Ishida $^{54}$ & 2003 & ICA & 104 & 66 & 22 & 0 & 89.6 & 85.2 & 74 & Stress CMR \\
\hline Jakljevic $^{55}$ & 2012 & FFR & 154 & 65 & NA & 0 & 87.0 & 67.0 & 35.1 & SPECT Vasodilator \\
\hline Jeetley $^{56}$ & 2006 & ICA & 123 & 62 & 46 & 33 & 85.9 & 50 & 69.1 & SPECT Vasodilator \\
\hline Johansen $^{57}$ & 2005 & ICA & 357 & 57 & 63 & 0 & 74.6 & 79.2 & 35.3 & SPECT Vasodilator \\
\hline Joutsiniemi $^{58}$ & 2014 & FFR & 104 & 64 & 62 & 0 & 94.6 & 86.6 & 35.6 & PET \\
\hline Kajander $^{59}$ & 2010 & FFR & 107 & 63 & 45 & 0 & 95 & 86.6 & 37.4 & CCTA \\
\hline Kajander $^{59}$ & 2010 & ICA & 104 & 63 & 45 & 0 & 94.7 & 90.9 & 36.5 & PET \\
\hline Kajinami $^{60}$ & 1995 & ICA & 251 & 56 & 30.7 & N/A & 73.7 & 75.4 & 53 & Stress ECG \\
\hline Kajinami $^{60}$ & 1995 & ICA & 251 & 56 & 32 & 0 & 82.7 & 59.3 & 53 & SPECT Exercise \\
\hline Kang $^{61}$ & 2013 & FFR & 700 & 62 & 30 & 0 & 71.4 & 60.6 & 38 & ICA \\
\hline Khattar 62 & 1998 & ICA & 100 & 62 & 30 & 28 & 67.6 & 80.8 & 74 & Echo Dobutamine \\
\hline Khattar $^{62}$ & 1998 & ICA & 100 & 62 & 30 & 70 & 69.6 & 40.9 & 56 & Stress ECG \\
\hline $\mathrm{Ko}^{63}$ & 2014 & FFR & 115 & 64 & 24 & 10 & 94.4 & 54.3 & 78.3 & CCTA \\
\hline Koskinen $^{64}$ & 1987 & ICA & 100 & 57 & 44.7 & N/A & 63.3 & 80 & 90 & Stress ECG \\
\hline Latcham $^{65}$ & 1995 & ICA & 106 & 63 & 39.3 & N/A & 74.4 & 65 & 81.1 & Echo Dobutamine \\
\hline Lipiec $^{66}$ & 2008 & ICA & 103 & 58 & 36 & 50 & 92.4 & 54.2 & 76.7 & SPECT Vasodilator \\
\hline Mahmarian $^{67}$ & 1990 & ICA & 360 & 56 & 26 & 22 & 86.9 & 86.7 & 74.7 & SPECT Exercise \\
\hline Mairesse $^{68}$ & 1994 & ICA & 129 & 56 & 30.2 & 0 & 75.9 & 84.8 & 64.3 & Echo Dobutamine \\
\hline Mairesse ${ }^{68}$ & 1994 & ICA & 129 & 56 & 26.4 & N/A & 42.2 & 82.6 & 64.3 & Stress ECG \\
\hline Manka $^{69}$ & 2015 & FFR & 150 & 63 & 30 & 0 & 84.7 & 90.8 & 56.7 & Stress CMR \\
\hline Manka $^{70}$ & 2012 & FFR & 120 & 64 & 25 & 0 & 89.9 & 82.4 & 57.5 & Stress CMR \\
\hline Marcovitz $^{71}$ & 1992 & ICA & 141 & 60 & 40.4 & 10.6 & 96.3 & 65.6 & 77.3 & Echo Dobutamine \\
\hline Marwick $^{72}$ & 1992 & ICA & 150 & 57 & 21.3 & N/A & 84.2 & 86.1 & 76 & Echo Exercise \\
\hline
\end{tabular}




\begin{tabular}{|c|c|c|c|c|c|c|c|c|c|c|}
\hline Marwick $^{73}$ & 1995 & ICA & 161 & 60 & 100 & 0 & 79.7 & 81.4 & 36.7 & Echo Exercise \\
\hline Marwick $^{74}$ & 1995 & ICA & 147 & 58 & 40.8 & 0 & 71 & 90.6 & 42.2 & Echo Exercise \\
\hline Marwick $^{75}$ & 1993 & ICA & 217 & 58 & 28.1 & 0 & 71.8 & 82.7 & 65.4 & Echo Dobutamine \\
\hline Meijboom $^{76}$ & 2007 & ICA & 104 & 58 & 27 & 0 & 100 & 75 & 84.6 & CCTA \\
\hline Meijboom $^{77}$ & 2007 & ICA & 123 & 62 & 100 & 0 & 100 & 75 & 51.2 & CCTA \\
\hline Meijboom $^{77}$ & 2007 & ICA & 279 & 58 & 0 & 0 & 98.9 & 89.9 & 68.1 & CCTA \\
\hline Meijboom $^{78}$ & 2008 & ICA & 360 & 60 & 32 & 0 & 99.2 & 64 & 68 & CCTA \\
\hline Merkle $^{79}$ & 2007 & ICA & 228 & 61 & 21 & 0 & 93 & 85.7 & 75.4 & Stress CMR \\
\hline Meuwissen $^{80}$ & 2002 & FFR & 151 & 60 & 29 & 38 & 69.2 & 76.7 & 34.4 & SPECT Vasodilator \\
\hline Michaelides ${ }^{81}$ & 1999 & ICA & 245 & 52 & 11 & 0 & 65.9 & 88.2 & 86.1 & Stress ECG \\
\hline Miller $^{82}$ & 1997 & ICA & 243 & 63 & 1.2 & 34.7 & 91.1 & 27.5 & 83.5 & SPECT Vasodilator \\
\hline Miller $^{83}$ & 2008 & ICA & 291 & 59 & 26 & 0 & 87.4 & 89.6 & 59.8 & CCTA \\
\hline Miyazono $^{84}$ & 1998 & ICA & 112 & 66 & 27.7 & N/A & 74.2 & 90 & 55.4 & Echo Vasodilator \\
\hline Mohiuddin $^{85}$ & 1996 & ICA & 202 & 58 & 41 & N/A & 90 & 85.7 & 79.2 & SPECT Vasodilator \\
\hline Motwani $^{86}$ & 2012 & ICA & 111 & 61 & 26 & 12 & 93.8 & 66.7 & 87.3 & Stress CMR \\
\hline Mouden $^{87}$ & 2014 & FFR & 100 & 66 & 36 & NA & 60 & 76.25 & 20 & SPECT Vasodilator \\
\hline Nagel $^{88}$ & 1999 & ICA & 163 & 60 & 29.3 & 0 & 74.3 & 81.5 & 66.9 & Echo Dobutamine \\
\hline Nallamothu ${ }^{89}$ & 1995 & ICA & 321 & 57 & 0.33 & 0 & 80.9 & 68.5 & 83.2 & SPECT Exercise \\
\hline Nallamothu ${ }^{89}$ & 1995 & ICA & 321 & 57 & 24.9 & N/A & 46.2 & 59.5 & 76.9 & Stress ECG \\
\hline Nedelikovic $^{90}$ & 2006 & ICA & 117 & 54 & 22 & 27.4 & 92.8 & 91.7 & 59 & Echo Vasodilator \\
\hline Nedelikovic $^{90}$ & 2006 & ICA & 117 & 54 & 22 & 27.4 & 89.9 & 87.5 & 59 & Echo Dobutamine \\
\hline Nedelikovic $^{90}$ & 2006 & ICA & 117 & 54 & 22 & 27.4 & 95.7 & 91.67 & 59 & Echo Dobutamine \\
\hline Norgaard $^{91}$ & 2014 & FFR & 254 & 64 & 36 & 2 & 93.8 & 33.9 & 31.5 & CCTA \\
\hline Norgaard $^{11}$ & 2014 & FFR & 254 & 62 & 36 & 2 & 63.8 & 82.8 & 31.5 & ICA \\
\hline Ostojic $^{92}$ & 1994 & ICA & 150 & 51 & 16.7 & 50.7 & 71 & 89.5 & 87.3 & Echo Vasodilator \\
\hline Ostojic $^{92}$ & 1994 & ICA & 150 & 51 & 16.7 & 50.7 & 74.8 & 79 & 87.3 & Echo Dobutamine \\
\hline PACIFIC trial ${ }^{33}$ & 2016 & FFR & 206 & 58 & 36 & 0 & 57.0 & 93.8 & 45.1 & SPECT Vasodilator \\
\hline PACIFIC trial ${ }^{93}$ & 2016 & FFR & 208 & 58 & 36 & 0 & 90.2 & 60.3 & 44.2 & CCTA \\
\hline PACIFIC trial ${ }^{93}$ & 2016 & FFR & 204 & 58 & 36 & 0 & 86.7 & 84.2 & 44.1 & PET \\
\hline Parodi $^{94}$ & 1999 & ICA & 101 & 55 & 19.8 & 0 & 77.5 & 76.2 & 79.2 & Echo Vasodilator \\
\hline
\end{tabular}




\begin{tabular}{|c|c|c|c|c|c|c|c|c|c|c|}
\hline Pasierski $^{95}$ & 2001 & ICA & 248 & 53 & 33 & 0 & 81.9 & 96.2 & 46.8 & Echo Exercise \\
\hline Pasierski $^{95}$ & 2001 & ICA & 248 & 53 & 33 & 0 & 74.1 & 97.7 & 46.8 & Echo Dobutamine \\
\hline Peteiro $^{96}$ & 2012 & ICA & 116 & 61 & 15.5 & 40.5 & 84 & 63.4 & 64.7 & Echo Exercise \\
\hline Picano ${ }^{97}$ & 1989 & ICA & 374 & 54 & 23.4 & 36 & 72.7 & 87.8 & 80.2 & Echo Vasodilator \\
\hline Picano $^{98}$ & 1993 & ICA & 178 & 58 & 15.6 & 0 & 72.3 & 95.8 & 73 & Echo Vasodilator \\
\hline Pilz $^{99}$ & 2006 & ICA & 171 & 62 & 37 & 28.1 & 96.5 & 82.8 & 66.1 & Stress CMR \\
\hline Pingitore $^{100}$ & 1996 & ICA & 110 & 60 & 16.7 & N/A & 81.5 & 94.4 & 83.6 & Echo Vasodilator \\
\hline Pingitore $^{100}$ & 1996 & ICA & 110 & 60 & 16.7 & 30 & 94.6 & 88.9 & 83.6 & Echo Dobutamine \\
\hline Porter $^{101}$ & 2011 & ICA & 100 & 62 & 40 & 29 & 59.6 & 72.9 & 52 & Echo Vasodilator \\
\hline Poyraz ${ }^{102}$ & 2014 & ICA & 281 & 62.6 & 61.2 & 0 & 86 & 94 & 27 & SPECT Vasodilator \\
\hline Psirropoulos $^{103}$ & 2002 & ICA & 606 & 54 & 52 & 19.8 & 93 & 43.8 & 19.6 & SPECT Exercise \\
\hline Quinones ${ }^{104}$ & 1992 & ICA & 112 & 57 & 33.2 & N/A & 74.4 & 88.5 & 76.8 & Echo Exercise \\
\hline Roger $^{105}$ & 1995 & ICA & 127 & N/A & N/A & N/A & 87.9 & 70 & 84.3 & Echo Exercise \\
\hline Roger ${ }^{106}$ & 1997 & ICA & 340 & 65 & 28.2 & 0 & 78.2 & 40.9 & 74.1 & Echo Exercise \\
\hline San Roman ${ }^{107}$ & 1996 & ICA & 102 & 62 & 43 & 0 & 77.8 & 97.4 & 61.8 & Echo Vasodilator \\
\hline San Roman ${ }^{108}$ & 1998 & ICA & 102 & 64 & 51 & 0 & 81.8 & 94.4 & 64.7 & Echo Vasodilator \\
\hline San Roman ${ }^{107}$ & 1996 & ICA & 102 & 62 & 43 & 0 & 77.8 & 94.9 & 61.8 & Echo Dobutamine \\
\hline San Roman ${ }^{108}$ & 1998 & ICA & 102 & 64 & 51 & 0 & 78.8 & 88.9 & 64.7 & Echo Dobutamine \\
\hline Santana Boada ${ }^{109}$ & 1998 & ICA & 163 & 60 & 38 & 0 & 91.7 & 89.6 & 58.9 & SPECT Vasodilator \\
\hline Santana-Boado ${ }^{109}$ & 1998 & ICA & 163 & 60 & 38.7 & 0 & 66.7 & 70.7 & 49.7 & Stress ECG \\
\hline Schaap ${ }^{110}$ & 2013 & FFR & 129 & 63 & 35 & 0 & 79.7 & 90.8 & 49.6 & SPECT Vasodilator \\
\hline Schwitter ${ }^{111}$ & 2013 & ICA & 425 & 61 & 33 & 27 & 59.2 & 72.2 & 48.5 & SPECT Vasodilator \\
\hline Schwitter ${ }^{111}$ & 2013 & ICA & 533 & 60 & 27 & 27 & 75.2 & 58.9 & 48.5 & Stress CMR \\
\hline Severi $^{112}$ & 1994 & ICA & 429 & 55 & 28.4 & 0 & 74.8 & 89.6 & 57.3 & Echo Vasodilator \\
\hline Shabestari ${ }^{113}$ & 2007 & ICA & 143 & 63 & 28 & 0 & 96.3 & 57.1 & 75.5 & CCTA \\
\hline Sharples ${ }^{114}$ & 2007 & ICA & 224 & NA & NA & 23 & 87.3 & 60.8 & 68.3 & SPECT Vasodilator \\
\hline Sharples ${ }^{114}$ & 2007 & ICA & 226 & 62 & 32 & 31 & 74 & 72.7 & 75.2 & Stress CMR \\
\hline Shelley ${ }^{115}$ & 2003 & ICA & 108 & 70 & NA & 0 & 94 & 79 & 59.3 & SPECT Vasodilator \\
\hline Shirai ${ }^{116}$ & 2002 & $\mathrm{ICA}$ & 603 & 63 & 3 & 31 & 44.7 & 96.5 & 39.3 & SPECT Exercise \\
\hline Slomka ${ }^{117}$ & 2006 & ICA & 174 & 63 & 33 & 0 & 83.9 & 81.1 & 78.7 & SPECT Vasodilator \\
\hline
\end{tabular}




\begin{tabular}{|c|c|c|c|c|c|c|c|c|c|c|}
\hline Smart $^{118}$ & 2000 & ICA & 386 & 61 & 34.5 & N/A & 85 & 86.8 & 72.5 & Echo Dobutamine \\
\hline Tadehara ${ }^{119}$ & 2008 & ICA & 101 & 72.1 & 48 & 19.7 & 93 & 70 & 53.4 & SPECT Vasodilator \\
\hline Takase $^{120}$ & 2004 & ICA & 102 & 66 & 17 & 44.1 & 93.4 & 84.6 & 74.5 & Stress CMR \\
\hline Takeuchi ${ }^{121}$ & 1993 & ICA & 120 & 63 & 25.8 & N/A & 85.1 & 93.5 & 61.7 & Echo Dobutamine \\
\hline Thompson $^{122}$ & 2005 & ICA & 116 & 60 & 30 & 0 & 86.4 & 78.6 & 75.9 & SPECT Vasodilator \\
\hline Watkins $^{123}$ & 2009 & FFR & 101 & 60 & 28 & 24 & 94.9 & 91.3 & 77.2 & Stress CMR \\
\hline Wolak $^{124}$ & 2008 & ICA & 114 & 65 & 100 & 0 & 79.7 & 73.3 & 60.5 & SPECT Vasodilator \\
\hline $\mathrm{Wu}^{125}$ & 2009 & ICA & 218 & 64 & 38 & 2.8 & 94.6 & 62.5 & 59.6 & SPECT Vasodilator \\
\hline Yoon $^{126}$ & 2009 & ICA & 344 & 63.3 & 63 & 0 & 87 & 34 & 63.7 & SPECT Vasodilator \\
\hline
\end{tabular}

\section{REFERENCES}

1. Amanullah AM, Berman DS, Kiat H, Friedman JD. Usefulness of hemodynamic changes during adenosine infusion in predicting the diagnostic accuracy of adenosine technetium-99m sestamibi single-photon emission computed tomography (SPECT). Am J Cardiol. 1997;79(10):1319-1322. doi:10.1016/S0002-9149(97)00132-X.

2. Anthopoulos LP, Bonou MS, Kardaras FG, et al. Stress echocardiography in elderly patients with coronary artery disease: Applicability, safety and prognostic value of dobutamine and adenosine echocardiography in elderly patients. J Am Coll Cardiol. 1996;28(1):52-59. doi:10.1016/0735-1097(96)00127-1.

3. Bateman TM, Heller G V., McGhie AI, et al. Diagnostic accuracy of rest/stress ECG-gated Rb-82 myocardial perfusion PET: Comparison with ECG-gated Tc-99m sestamibi SPECT. J Nucl Cardiol. 2006;13(1):24-33. doi:10.1016/j.nuclcard.2005.12.004.

4. Beleslin BDD, Ostojic M, Stepanovic J, et al. Stress echocardiography in the detection of myocardial ischemia: Head-to-head comparison of exercise, dobutamine, and dipyridamole tests. Circulation. 1994;90(3):1168-1176. doi:10.1161/01.CIR.90.3.1168.

5. Berman DS, Kang X, Nishina H, et al. Diagnostic accuracy of gated Tc-99m sestamibi stress myocardial perfusion SPECT with combined supine and prone acquisitions to detect coronary artery disease in obese and nonobese patients. J Nucl Cardiol. 2006;13(2):191-201. doi:10.1016/j.nuclcard.2006.01.020.

6. Bernhardt P, Spiess J, Levenson B, et al. Combined assessment of myocardial perfusion and late gadolinium enhancement in patients after percutaneous coronary intervention or bypass grafts: a multicenter study of an integrated cardiovascular magnetic resonance protocol. J Am Coll Cardiol Img. 2009;2(11):1292-1300. doi:10.1016/j.jcmg.2009.05.011.

7. Bettencourt N, Chiribiri A, Schuster A, et al. Direct comparison of cardiac magnetic resonance and multidetector computed tomography stress-rest perfusion imaging for detection of coronary artery disease. J Am Coll Cardiol. 2013;61(10):1099-1107. doi:10.1016/j.jacc.2012.12.020.

8. Beygui F, Le Feuvre C, Maunoury C, et al. Detection of coronary restenosis by exercise electrocardiography thallium-201 perfusion imaging and coronary angiography in asymptomatic patients after percutaneous transluminal coronary angioplasty. Am J Cardiol. 2000;86(1):35-40. doi:10.1016/s0002-9149(00)00825-0.

9. Bokhari S, Shahzad A, Bergmann SR. Superiority of exercise myocardial perfusion imaging compared with the exercise ECG in the diagnosis of coronary artery disease. Coron Artery Dis. 2008;19(6):399-404. doi:10.1097/MCA.0b013e3283021ab4.

10. Budoff MJ, Dowe D, Jollis JG, et al. Diagnostic performance of 64-multidetector row coronary computed tomographic angiography for evaluation of coronary artery stenosis in individuals without known coronary artery disease: results from the prospective multicenter ACCURACY (Assessment by Coro. J Am Coll Cardiol. 2008;52(21):1724-1732. doi:10.1016/j.jacc.2008.07.031.

11. Celutkiene J, Zakarkaite D, Skorniakov V, et al. Quantitative approach using multiple single parameters versus visual assessment in dobutamine stress 
echocardiography. Cardiovasc Ultrasound. 2012;10:31. doi:10.1186/1476-7120-10-31.

12. Chae SC, Heo J, Iskandrian AS, Wasserleben V, Cave V. Identification of extensive coronary artery disease in women by exercise single-photon emission computed tomographic (SPECT) thallium imaging. J Am Coll Cardiol. 1993;21(6):1305-1311. doi:10.1016/0735-1097(93)90301-G.

13. Chen MY, Bandettini WP, Shanbhag SM, et al. Concordance and diagnostic accuracy of vasodilator stress cardiac MRI and 320-detector row coronary CTA. Int J Cardiovasc Imaging. 2014;30(1):109-119. doi:10.1007/s10554-013-0300-0.

14. Christian TF, Miller TD, Bailey KR, Gibbons RJ. Noninvasive identification of severe coronary artery disease using exercise tomographic thallium-201 imaging. Am J Cardiol. 1992;70(1):14-20. doi:10.1016/0002-9149(92)91382-E.

15. Crouse LJ, Harbrecht JJ, Vacek JL, Rosamond TL, Kramer PH. Exercise echocardiography as a screening test for coronary artery disease and correlation with coronary arteriography. Am J Cardiol. 1991;67(15):1213-1218.

16. Danad I, Uusitalo V, Kero T, et al. Quantitative assessment of myocardial perfusion in the detection of significant coronary artery disease: cutoff values and diagnostic accuracy of quantitative [(15)O]H2O PET imaging. J Am Coll Cardiol. 2014;64(14):1464-1475. doi:10.1016/j.jacc.2014.05.069.

17. Danad I, Raijmakers PG, Appelman YE, et al. Hybrid Imaging Using Quantitative H215O PET and CT-Based Coronary Angiography for the Detection of Coronary Artery Disease. J Nucl Med. 2013:55-64. doi:10.2967/jnumed.112.104687.

18. Daou D, Delahaye N, Vilain D, Lebtahi R, Faraggi M, Guludec D Le. Identification of extensive coronary artery disease: Incremental value of exercise TI-201 SPECT to clinical and stress test variables. J Nucl Cardiol. 2002;9(2):161-168. doi:10.1067/mnc.2002.119974.

19. Min JK, Leipsic J, Pencina MJ, et al. Diagnostic accuracy of fractional flow reserve from anatomic CT angiography. JAMA. 2012;308(12):1237-1245. doi:10.1001/2012.jama.11274.

20. Koo BK, Erglis A, Doh JH, et al. Diagnosis of ischemia-causing coronary stenoses by noninvasive fractional flow reserve computed from coronary computed tomographic angiograms: Results from the prospective multicenter DISCOVER-FLOW (Diagnosis of Ischemia-Causing Stenoses Obtained Via Noni. J Am Coll Cardiol. 2011;58(19):1989-1997. doi:10.1016/j.jacc.2011.06.066.

21. Dolan MS, Riad K, El-Shafei A, et al. Effect of intravenous contrast for left ventricular opacification and border definition on sensitivity and specificity of dobutamine stress echocardiography compared with coronary angiography in technically difficult patients. Am Heart J. 2001;142(5):908-915. doi:10.1067/mhj.2001.117608.

22. Dondi M, Fagioli G, Salgarello M, Zoboli S, Nanni C, Cidda C. Myocardial SPECT: what do we gain from attenuation correction (and when)? $Q J$ Nucl Med Mol Imaging. 2004;48(3):181-187.

23. Doyle M, Fuisz A, Kortright E, et al. The impact of myocardial flow reserve on the detection of coronary artery disease by perfusion imaging methods: an NHLBI WISE study. J Cardiovasc Magn Reson. 2003;5(3):475-485. doi:10.1081/JCMR-120022263.

24. Ebersberger U, Makowski MR, Schoepf UJ, et al. Magnetic resonance myocardial perfusion imaging at 3.0 Tesla for the identification of myocardial ischaemia: comparison with coronary catheter angiography and fractional flow reserve measurements. Eur Heart J Cardiovasc Imaging. 2013;14(12):1174-1180. doi:10.1093/ehjci/jet074.

25. Elhendy A, yan Domburg RT, Roelandt JR, et al. Accuracy of dobutamine stress echocardiography for the diagnosis of coronary artery stenosis in patients with myocardial infarction: the impact of extent and severity of left ventricular dysfunction. Heart. 1996;76(2):123-128.

26. Elhendy A, van Domburg RT, Bax JJ, et al. Optimal criteria for the diagnosis of coronary artery disease by dobutamine stress echocardiography. Am J Cardiol. 1998;82(11):1339-1344. doi:S0002-9149(98)00638-9 [pii].

27. Elhendy A, van Domburg RT, Poldermans D, et al. Safety and feasibility of dobutamine-atropine stress echocardiography for the diagnosis of coronary artery disease in diabetic patients unable to perform an exercise stress test. Diabetes Care. 1998;21(11):1797-1802. doi:10.2337/diacare.21.11.1797.

28. Emmett L, Iwanochko RM, Freeman MR, Barolet A, Lee DS, Husain M. Reversible regional wall motion abnormalities on exercise technetium-99m-gated cardiac single photon emission computed tomography predict high-grade angiographic stenoses. J Am Coll Cardiol. 2002;39(6):991-998. doi:10.1016/S0735-1097(02)017072 .

29. Neglia D, Rovai D, Caselli C, et al. Detection of significant coronary artery disease by noninvasive anatomical and functional imaging. Circ Cardiovasc Imaging. 
2015;8(3):e002179-e002179. doi:10.1161/CIRCIMAGING.114.002179.

30. Ferrara N, Leosco D, Abete P, et al. Dipyridamole echocardiography as a useful and safe test in the assessment of coronary artery disease in the elderly. $J$ Am Geriatr Soc. 1991;39(10):993-999. doi:10.1111/j.1532-5415.1991.tb04046.x.

31. Fragasso G, Lu C, Dabrowski P, Pagnotta P, Sheiban I, Chierchia SL. Comparison of stress/rest myocardial perfusion tomography, dipyridamole and dobutamine stress echocardiography for the detection of coronary disease in hypertensive patients with chest pain and positive exercise test. J Am Coll Cardiol. 1999;34(2):441447. doi:10.1016/S0735-1097(99)00231-4.

32. Gallowitsch HJ, Sykora J, Mikosch P, et al. Attenuation-corrected thallium-201 single-photon emission tomography using a gadolinium-153 moving line source: Clinical value and the impact of attenuation correction on the extent and severity of perfusion abnormalities. Eur J Nucl Med. 1998;25(3):220-228. doi:10.1007/s002590050220.

33. Greenwood JP, Maredia N, Younger JF, et al. Cardiovascular magnetic resonance and single-photon emission computed tomography for diagnosis of coronary heart disease (CE-MARC): A prospective trial. Lancet. 2012;379(9814):453-460. doi:10.1016/S0140-6736(11)61335-4.

34. Geleijnse ML, Marwick TH, Boersma E, Deckers JW, Melin JA, Fioretti PM. Optimal pharmacological stress testing for the diagnosis of coronary artery disease: a probabilistic approach. Eur Heart J. 1995;16 Suppl M(SUPPL. M):3-10.

35. Gentile R, Vitarelli A, Schillaci O, et al. Diagnostic accuracy and prognostic implications of stress testing for coronary artery disease in the elderly. Ital Heart J. 2001;2(7):539-545.

36. Go RT, Marwick TH, MacIntyre WJ, et al. A prospective comparison of rubidium-82 PET and thallium-201 SPECT myocardial perfusion imaging utilizing a single dipyridamole stress in the diagnosis of coronary artery disease. J Nucl Med. 1990;31(12):1899-1905.

37. González P, Massardo T, Jofré MJ, et al. 201Tl myocardial SPECT detects significant coronary artery disease between 50\% and 75\% angiogram stenosis. Rev Esp Med Nucl. 2005;24(5):305-311. doi:10.1157/13079281.

38. Groothuis JGJ, Beek AM, Brinckman SL, et al. Combined non-invasive functional and anatomical diagnostic work-up in clinical practice: The magnetic resonance and computed tomography in suspected coronary artery disease (MARCC) study. Eur Heart J. 2013;34(26):1990-1998. doi:10.1093/eurheartj/eht077.

39. Groutars RGEJ, Verzijlbergen JF, Tiel-van Buul MMC, et al. The accuracy of 1-day dual-isotope myocardial SPECT in a population with high prevalence of coronary artery disease. Int J Cardiovasc Imaging. 2003;19(3):229-238.

40. Gueret P, Deux J-F, Bonello L, et al. Diagnostic performance of computed tomography coronary angiography (from the Prospective National Multicenter Multivendor EVASCAN Study). Am J Cardiol. 2013;111(4):471-478. doi:10.1016/j.amjcard.2012.10.029.

41. Hamasaki S, Arima S, Tahara M, et al. Increase in the delta ST/delta heart rate (HR) index: a new predictor of restenosis after successful percutaneous transluminal coronary angioplasty. Am J Cardiol. 1996;78(9):990-995.

42. Hambye A-SE, Vervaet AM, Dobbeleir AA. Head-to-head comparison of uncorrected and scatter corrected, summed and end diastolic myocardial perfusion SPECT in coronary artery disease. Nucl Med Commun. 2004;25(4):347-353. doi:10.1097/00006231-200404000-00006.

43. Hanekom L, Cho G-Y, Leano R, Jeffriess L, Marwick TH. Comparison of two-dimensional speckle and tissue Doppler strain measurement during dobutamine stress echocardiography: an angiographic correlation. Eur Heart J. 2007;28(14):1765-1772. doi:10.1093/eurheartj/ehm188.

44. Hecht HS, DeBord L, Shaw R, et al. Digital supine bicycle stress echocardiography: a new technique for evaluating coronary artery disease. $J$ Am Coll Cardiol. 1993;21(4):950-956. doi:10.1016/0735-1097(93)90352-2.

45. Hecht HS, DeBord L, Sotomayor N, Shaw R, Dunlap R, Ryan C. Supine bicycle stress echocardiography: peak exercise imaging is superior to postexercise imaging. $J$ Am Soc Echocardiogr. 1993;6(3 Pt 1):265-271. doi:http://dx.doi.org/10.1016/S0894-7317(14)80062-X.

46. Hecht HS, Shaw RE, Bruce TR, Ryan C, Stertzer SH, Myler RK. Usefulness of tomographic thallium-201 imaging for detection of restenosis after percutaneous transluminal coronary angioplasty. Am J Cardiol. 1990;66(19):1314-1318.

47. Hennessy TG, Codd MB, Kane G, McCarthy C, McCann HA, Sugrue DD. Dobutamine stress echocardiography in the detection of coronary artery disease: importance of the pretest likelihood of disease. Am Heart J. 1997;134(4):685-692. doi:10.1016/S0002-8703(97)70052-8 
48. Hennessy TG, Siobhan Hennessy M, Codd MB, et al. Detection of coronary artery disease using dobutamine stress echocardiography in patients with an abnormal resting electrocardiograph. Int J Cardiol. 1998;64(3):293-298.

49. Hida S, Chikamori T, Tanaka H, et al. Diagnostic value of left ventricular function after adenosine triphosphate loading and at rest in the detection of multi-vessel coronary artery disease using myocardial perfusion imaging. J Nucl Cardiol. 2009;16(1):20-27. doi:10.1007/s12350-008-9003-7.

50. Ho YL, Wu CC, Lin LC, et al. Assessment of the functional significance of coronary artery stenosis by dobutamine-atropine stress echocardiography. Cardiology. 1997;88(4):386-392.

51. Hoffmann R, Lethen H, Marwick T, et al. Analysis of interinstitutional observer agreement in interpretation of dobutamine stress echocardiograms. $J$ Am Coll Cardiol. 1996;27(2):330-336. doi:10.1016/0735-1097(95)00483-1.

52. Hoffmann R, Lethen H, Kühl H, Lepper W, Hanrath P. Extent and severity of test positivity during dobutamine stress echocardiography. Influence on the predictive value for coronary artery disease. Eur Heart J. 1999;20(20):1485-1492. doi:10.1053/euhj.1999.1628.

53. Hung G-U, Lee K-W, Chen C-P, Yang K-T, Lin W-Y. Worsening of left ventricular ejection fraction induced by dipyridamole on Tl-201 gated myocardial perfusion imaging predicts significant coronary artery disease. J Nucl Cardiol. 2006;13(2):225-232. doi:10.1016/j.nuclcard.2006.01.007.

54. Ishida N, Sakuma H, Motoyasu M, et al. Noninfarcted myocardium: correlation between dynamic first-pass contrast-enhanced myocardial MR imaging and quantitative coronary angiography. Radiology. 2003;229(1):209-216. doi:10.1148/radiol.2291021118.

55. Jakljević T, Ruzić A, Bazdarić K, et al. Detection of myocardial ischemia in diabetic patients: the limitations of myocardial perfusion imaging. Coll Antropol. 2012;36(3):821-826.

56. Jeetley P, Hickman M, Kamp O, et al. Myocardial contrast echocardiography for the detection of coronary artery stenosis: a prospective multicenter study in comparison with single-photon emission computed tomography. J Am Coll Cardiol. 2006;47(1):141-145. doi:10.1016/j.jacc.2005.08.054.

57. Johansen A, Høilund-Carlsen PF, Christensen HW, et al. Diagnostic accuracy of myocardial perfusion imaging in a study population without post-test referral bias. $J$ Nucl Cardiol. 2005;12(5):530-537. doi:10.1016/j.nuclcard.2005.04.012.

58. Joutsiniemi E, Saraste A, Pietilä M, et al. Absolute flow or myocardial flow reserve for the detection of significant coronary artery disease? Eur Heart J Cardiovasc Imaging. 2014;15(6):659-665. doi:10.1093/ehjci/jet274.

59. Kajander S, Joutsiniemi E, Saraste M, et al. Cardiac positron emission tomography/computed tomography imaging accurately detects anatomically and functionally significant coronary artery disease. Circulation. 2010;122(6):603-613. doi:10.1161/CIRCULATIONAHA.109.915009.

60. Kajinami K, Seki H, Takekoshi N, Mabuchi H. Noninvasive prediction of coronary atherosclerosis by quantification of coronary artery calcification using electron beam computed tomography: comparison with electrocardiographic and thallium exercise stress test results. J Am Coll Cardiol. 1995;26(5):1209-1221. doi:10.1016/0735-1097(95)00314-2.

61. Kang S-J, Ahn J-M, Han S, et al. Sex differences in the visual-functional mismatch between coronary angiography or intravascular ultrasound versus fractional flow reserve. JACC Cardiovasc Interv. 2013;6(6):562-568. doi:10.1016/j.jcin.2013.02.016.

62. Khattar RS, Senior R, Lahiri a. Assessment of myocardial perfusion and contractile function by inotropic stress Tc-99m sestamibi SPECT imaging and echocardiography for optimal detection of multivessel coronary artery disease. Heart. 1998;79(3):274-280.

63. Ko BS, Wong DTL, Cameron JD, et al. 320-row CT coronary angiography predicts freedom from revascularisation and acts as a gatekeeper to defer invasive angiography in stable coronary artery disease: A fractional flow reserve-correlated study. Eur Radiol. 2014;24(3):738-747. doi:10.1007/s00330-013-3059-8.

64. Koskinen M, Pöyhönen L, Seppänen S. Thallium-201 washout in coronary artery disease using SPECT--a comparison with coronary angiography. Eur J Nucl Med. 1987;12(12):609-612.

65. Latcham AP, Orsinelli DA, Pearson AC. Recognition of the segmental tendency of false-positive dobutamine stress echocardiograms and its effects on test sensitivity and specificity. Am Heart J. 1995;129(5):1047-1050.

66. Lipiec P, Wejner-Mik P, Krzemińska-Pakuła M, et al. Accelerated stress real-time myocardial contrast echocardiography for the detection of coronary artery disease: comparison with 99mTc single photon emission computed tomography. J Am Soc Echocardiogr. 2008;21(8):941-947. doi:10.1016/j.echo.2008.02.004. 
67. Mahmarian JJ, Boyce TM, Goldberg RK, Cocanougher MK, Roberts R, Verani MS. Quantitative exercise thallium-201 single photon emission computed tomography for the enhanced diagnosis of ischemic heart disease. J Am Coll Cardiol. 1990;15(2):318-329. doi:10.1016/S0735-1097(10)80055-5.

68. Mairesse GH, Marwick TH, Vanoverschelde JLJ, et al. How accurate is dobutamine stress electrocardiography for detection of coronary artery disease?. Comparison with two-dimensional echocardiography and technetium-99m methoxyl isobutyl isonitrile (mibi) perfusion scintigraphy. J Am Coll Cardiol. 1994;24(4):920-927. doi:10.1016/0735-1097(94)90850-8.

69. Manka R, Wissmann L, Gebker R, et al. Multicenter Evaluation of Dynamic Three-Dimensional Magnetic Resonance Myocardial Perfusion Imaging for the Detection of Coronary Artery Disease Defined by Fractional Flow Reserve. Circ Cardiovasc Imaging. 2015;8(5). doi:10.1161/CIRCIMAGING.114.003061.

70. Manka R, Paetsch I, Kozerke S, et al. Whole-heart dynamic three-dimensional magnetic resonance perfusion imaging for the detection of coronary artery disease defined by fractional flow reserve: Determination of volumetric myocardial ischaemic burden and coronary lesion location. Eur Heart J. 2012;33(16):2016-2024. doi:10.1093/eurheartj/ehs170

71. Marcovitz P a, Armstrong WF. Accuracy of dobutamine stress echocardiography in detecting coronary artery disease. Am J Cardiol. 1992;69(16):1269-1273. doi:10.1016/0002-9149(92)91219-T.

72. Marwick TH, Nemec JJ, Pashkow FJ, Stewart WJ, Salcedo EE. Accuracy and limitations of exercise echocardiography in a routine clinical setting. J Am Coll Cardiol. 1992;19(1):74-81. doi:10.1016/0735-1097(92)90054-Q.

73. Marwick TH, Anderson T, Williams MJ, et al. Exercise echocardiography is an accurate and cost-efficient technique for detection of coronary artery disease in women. J Am Coll Cardiol. 1995;26(2):335-341. doi:10.1016/0735-1097(95)80004-Z.

74. Marwick TH, Torelli J, Harjai K, et al. Influence of left ventricular hypertrophy on detection of coronary artery disease using exercise echocardiography. $J$ Am Coll Cardiol. 1995;26(5):1180-1186. doi:10.1016/0735-1097(96)81472-0.

75. Marwick T, D'Hondt AM, Baudhuin T, et al. Optimal use of dobutamine stress for the detection and evaluation of coronary artery disease: combination with echocardiography or scintigraphy, or both? J Am Coll Cardiol. 1993;22(1):159-167. doi:10.1016/0735-1097(93)90830-T.

76. Meijboom WB, Mollet NR, Van Mieghem CA, et al. 64-Slice CT coronary angiography in patients with non-ST elevation acute coronary syndrome. Heart. 2007;93(11):1386-1392. doi:10.1136/hrt.2006.112771.

77. Meijboom WB, Weustink AC, Pugliese F, et al. Comparison of Diagnostic Accuracy of 64-Slice Computed Tomography Coronary Angiography in Women Versus Men With Angina Pectoris. Am J Cardiol. 2007;100(10):1532-1537. doi:10.1016/j.amjcard.2007.06.061.

78. Meijboom WB, Meijs MFL, Schuijf JD, et al. Diagnostic Accuracy of 64-Slice Computed Tomography Coronary Angiography. A Prospective, Multicenter, Multivendor Study. J Am Coll Cardiol. 2008;52(25):2135-2144. doi:10.1016/j.jacc.2008.08.058

79. Merkle N, Wöhrle J, Grebe O, et al. Assessment of myocardial perfusion for detection of coronary artery stenoses by steady-state, free-precession magnetic resonance first-pass imaging. Heart. 2007;93(11):1381-1385. doi:10.1136/hrt.2006.104232.

80. Meuwissen M, Siebes M, Chamuleau SAJ, et al. Hyperemic stenosis resistance index for evaluation of functional coronary lesion severity. Circulation. 2002;106(4):441-446. doi:10.1161/01.CIR.0000023041.26199.29.

81. Michaelides a P, Psomadaki ZD, Dilaveris PE, et al. Improved detection of coronary artery disease by exercise electrocardiography with the use of right precordial leads. N Engl J Med. 1999;340(5):340-345. doi:10.1056/NEJM199902043400502.

82. Miller DD, Younis LT, Chaitman BR, Stratmann H. Diagnostic accuracy of dipyridamole technetium 99m-labeled sestamibi myocardial tomography for detection of coronary artery disease. J Nucl Cardiol. 1997;4(1 I):18-24. doi:10.1016/S1071-3581(97)90045-3.

83. Miller JM, Rochitte CE, Dewey M, et al. Diagnostic Performance of Coronary Angiography by 64-Row CT. N Engl J Med. 2008;359(22):2324-2336. doi:10.1056/NEJMoa0806576.

84. Miyazono Y, Kisanuki A, Toyonaga K, et al. Usefulness of adenosine triphosphate-atropine stress echocardiography for detecting coronary artery stenosis. Am $J$ Cardiol. 1998;82(3):290-294. doi:10.1016/S0002-9149(98)00345-2.

85. Mohiuddin SM, Ravage CK, Esterbrooks DJ, Lucas BD, Hilleman DE. The comparative safety and diagnostic accuracy of adenosine myocardial perfusion imaging in 
women versus men. Pharmacotherapy. 1989;16(4):646-651.

86. Motwani M, Maredia N, Fairbairn TA, et al. High-resolution versus standard-resolution cardiovascular MR myocardial perfusion imaging for the detection of coronary artery disease. Circ Cardiovasc Imaging. 2012;5(3):306-313. doi:10.1161/CIRCIMAGING.111.971796.

87. Mouden M, Ottervanger JP, Knollema S, et al. Myocardial perfusion imaging with a cadmium zinc telluride-based gamma camera versus invasive fractional flow reserve. Eur J Nucl Med Mol Imaging. 2014;41(5):956-962. doi:10.1007/s00259-013-2630-5.

88. Nagel E, Lehmkuhl HB, Klein C, et al. [Influence of image quality on the diagnostic accuracy of dobutamine stress magnetic resonance imaging in comparison with dobutamine stress echocardiography for the noninvasive detection of myocardial ischemia]. Z Kardiol. 1999;88(9):622-630. doi:90880622.392 [pii].

89. Nallamothu N, Ghods M, Heo J, Iskandrian AS. Comparison of thallium-201 single-photon emission computed tomography and electrocardiographic response during exercise in patients with normal rest electrocardiographic results. J Am Coll Cardiol. 1995;25(4):830-836. doi:http://dx.doi.org/10.1016/0735-1097(94)00471-2.

90. Nedeljkovic I, Ostojic M, Beleslin B, et al. Comparison of exercise, dobutamine-atropine and dipyridamole-atropine stress echocardiography in detecting coronary artery disease. Cardiovasc Ultrasound. 2006;4:22. doi:10.1186/1476-7120-4-22.

91. Nørgaard BL, Leipsic J, Gaur S, et al. Diagnostic performance of noninvasive fractional flow reserve derived from coronary computed tomography angiography in suspected coronary artery disease: the NXT trial (Analysis of Coronary Blood Flow Using CT Angiography: Next Steps). J Am Coll Cardiol. 2014;63(12):1145-1155. doi:10.1016/j.jacc.2013.11.043.

92. Ostojic M, Picano E, Beleslin B, et al. Dipyridamole-dobutamine echocardiography: a novel test for the detection of milder forms of coronary artery disease. $J$ Am Coll Cardiol. 1994;23(5):1115-1122. doi:10.1016/0735-1097(94)90599-1.

93. Danad I, Raijmakers PG, Driessen RS, et al. Comparison of Coronary CT Angiography, SPECT, PET, and Hybrid Imaging for Diagnosis of Ischemic Heart Disease Determined by Fractional Flow Reserve. JAMA Cardiol. 2017;2(10):1100-1107. doi:10.1001/jamacardio.2017.2471.

94. Parodi G, Picano E, Marcassa C, et al. High dose dipyridamole myocardial imaging: simultaneous sestamibi scintigraphy and two-dimensional echocardiography in the detection and evaluation of coronary artery disease. Italian Group of Nuclear Cardiology. Coron Artery Dis. 1999;10(3):177-184.

95. Pasierski T, Szwed H, Malczewska B, et al. Advantages of exercise echocardiography in comparison to dobutamine echocardiography in the diagnosis of coronary artery disease in hypertensive subjects. J Hum Hypertens. 2001;15(11):805-809. doi:10.1038/sj.jhh.1001265.

96. Peteiro J, Bouzas-Mosquera A, Estevez R, Pazos P, Piñeiro M, Castro-Beiras A. Head-to-head comparison of peak supine bicycle exercise echocardiography and treadmill exercise echocardiography at peak and at post-exercise for the detection of coronary artery disease. J Am Soc Echocardiogr. 2012;25(3):319-326. doi:10.1016/j.echo.2011.11.002.

97. Picano E, Severi S, Michelassi C, et al. Prognostic importance of dipyridamole-echocardiography test in coronary artery disease. Circulation. 1989;80(3):450-457.

98. Picano E, Pingitore A, Conti U, et al. Enhanced sensitivity for detection of coronary artery disease by addition of atropine to dipyridamole echocardiography. Eur Heart J. 1993;14(9):1216-1222.

99. Pilz G, Bernhardt P, Klos M, Ali E, Wild M, Höfling B. Clinical implication of adenosine-stress cardiac magnetic resonance imaging as potential gatekeeper prior to invasive examination in patients with AHA/ACC class II indication for coronary angiography. Clin Res Cardiol. 2006;95(10):531-538. doi:10.1007/s00392-0060422-7.

100. Pingitore A, Picano E, Colosso MQ, et al. The atropine factor in pharmacologic stress echocardiography. Echo Persantine (EPIC) and Echo Dobutamine International Cooperative (EDIC) Study Groups. J Am Coll Cardiol. 1996;27(5):1164-1170. doi:10.1016/0735-1097(95)00586-2.

101. Porter TR, Adolphson M, High RR, et al. Rapid detection of coronary artery stenoses with real-time perfusion echocardiography during regadenoson stress. Circ Cardiovasc Imaging. 2011;4(6):628-635. doi:10.1161/CIRCIMAGING.111.966341.

102. Yıldırım Poyraz N, Özdemir E, Poyraz BM, Kandemir Z, Keskin M, Türkölmez Ş. Predictors and Diagnostic Significance of the Adenosine Related Side Effects on Myocardial Perfusion SPECT/CT Imaging. Mol Imaging Radionucl Ther. 2014;23(3):89-95. doi:10.4274/mirt.85057.

103. Psirropoulos D, Efthimiadis A, Boudonas G, et al. Detection of myocardial ischemia in the elderly versus the young by stress thallium-201 scintigraphy and its relation to important coronary artery disease. Heart Vessels. 2002;16(4):131-136. doi:10.1007/s003800200009. 
104. Quinones MA, Verani MS, Haichin RM, Mahmarian JJ, Suarez J, Zoghbi WA. Exercise echocardiography versus $201 \mathrm{Tl}$ single-photon emission computed tomography in evaluation of coronary artery disease. Analysis of 292 patients. Circulation. 1992;85(3):1026-1031. doi:10.1161/01.CIR.85.3.1026.

105. Roger VL, Pellikka PA, Oh JK, Miller FA, Seward JB, Tajik AJ. Stress echocardiography. Part I. Exercise echocardiography: techniques, implementation, clinical applications, and correlations. Mayo Clin Proc. 1995;70(1):5-15. doi:10.1016/S0025-6196(11)64659-4.

106. Roger VL, Pellikka PA, Bell MR, Chow CW, Bailey KR, Seward JB. Sex and test verification bias. Impact on the diagnostic value of exercise echocardiography. Circulation. 1997;95(2):405-410. doi:10.1161/01.CIR.95.2.405.

107. San Roman JA, Vilacosta I, Castillo JA, et al. Dipyridamole and dobutamine-atropine stress echocardiography in the diagnosis of coronary artery disease: comparison with exercise stress test, analysis of agreement, and impact of antianginal treatment. Chest. 1996;110(5):1248-1254.

108. San Román JA, Vilacosta I, Castillo JA, et al. Selection of the optimal stress test for the diagnosis of coronary artery disease. Heart. 1998;80(4):370-376. doi:10.1136/hrt.80.4.370.

109. Santana-Boado C, Candell-Riera J, Castell-Conesa J, et al. Diagnostic accuracy of technetium-99m-MIBI myocardial SPECT in women and men. J Nucl Med. 1998;39(5):751-755.

110. Schaap J, Kauling RM, Boekholdt SM, et al. Usefulness of coronary calcium scoring to myocardial perfusion SPECT in the diagnosis of coronary artery disease in a predominantly high risk population. Int J Cardiovasc Imaging. 2013;29(3):677-684. doi:10.1007/s10554-012-0118-1.

111. Schwitter J, Wacker CM, Wilke N, et al. MR-IMPACT II: Magnetic Resonance Imaging for Myocardial Perfusion Assessment in Coronary artery disease Trial: perfusion-cardiac magnetic resonance vs. single-photon emission computed tomography for the detection of coronary artery disease: a comparative. Eur Heart J. 2013;34(10):775-781. doi:10.1093/eurheartj/ehs022.

112. Severi S, Picano E, Michelassi C, et al. Diagnostic and prognostic value of dipyridamole echocardiography in patients with suspected coronary artery disease. Comparison with exercise electrocardiography. Circulation. 1994;89(3):1160-1173. doi:10.1161/01.CIR.89.3.1160.

113. Shabestari AA, Abdi S, Akhlaghpoor S, et al. Diagnostic performance of 64-channel multislice computed tomography in assessment of significant coronary artery disease in symptomatic subjects. Am J Cardiol. 2007;99(12):1656-1661. doi:10.1016/j.amjcard.2007.01.040.

114. Sharples L, Hughes V, Crean A, et al. Cost-effectiveness of functional cardiac testing in the diagnosis and management of coronary artery disease: a randomised controlled trial. The CECaT trial. Health Technol Assess. 2007;11(49):iii-iv, ix-115. doi:10.3310/hta11490.

115. Shelley S, Sathyamurthy I, Madhavan, Subramanyan K, Najeeb OM, Ramachandran P. Adenosine myocardial SPECT--its efficacy and safety and correlation with coronary angiogram. J Assoc Physicians India. 2003;51:557-560.

116. Shirai N, Yamagishi H, Yoshiyama M, et al. Incremental value of assessment of regional wall motion for detection of multivessel coronary artery disease in exercise (201)Tl gated myocardial perfusion imaging. J Nucl Med. 2002;43(4):443-450.

117. Slomka PJ, Fish MB, Lorenzo S, et al. Simplified normal limits and automated quantitative assessment for attenuation-corrected myocardial perfusion SPECT. J Nucl Cardiol. 2006;13(5):642-651. doi:10.1016/j.nuclcard.2006.06.131.

118. Smart SC, Knickelbine T, Malik F, Sagar KB. Dobutamine-atropine stress echocardiography for the detection of coronary artery disease in patients with left ventricular hypertrophy. Importance of chamber size and systolic wall stress. Circulation. 2000;101(3):258-263.

119. Tadehara F, Yamamoto H, Tsujiyama S, et al. Feasibility of a rapid protocol of 1-day single-isotope rest/adenosine stress Tc-99m sestamibi ECG-gated myocardial perfusion imaging. J Nucl Cardiol. 2008;15(1):35-41. doi:10.1016/j.nuclcard.2007.10.005.

120. Takase B, Nagata M, Kihara T, et al. Whole-heart dipyridamole stress first-pass myocardial perfusion MRI for the detection of coronary artery disease. Jpn Heart J. 2004;45(3):475-486. doi:10.1536/jhj.45.475.

121. Takeuchi M, Araki M, Nakashima Y, Kuroiwa A. Comparison of dobutamine stress echocardiography and stress thallium-201 single-photon emission computed tomography for detecting coronary artery disease. J Am Soc Echocardiogr. 6(6):593-602.

122. Thompson RC, Heller G V., Johnson LL, et al. Value of attenuation correction on ECG-gated SPECT myocardial perfusion imaging related to body mass index. $J$ Nucl Cardiol. 2005;12(2):195-202. doi:10.1016/j.nuclcard.2004.12.298. 
123. Watkins S, McGeoch R, Lyne J, et al. Validation of magnetic resonance myocardial perfusion imaging with fractional flow reserve for the detection of significant coronary heart disease. Circulation. 2009;120(22):2207-2213. doi:10.1161/CIRCULATIONAHA.109.872358.

124. Wolak A, Slomka PJ, Fish MB, Lorenzo S, Berman DS, Germano G. Quantitative diagnostic performance of myocardial perfusion SPECT with attenuation correction in women. J Nucl Med. 2008;49(6):915-922. doi:10.2967/jnumed.107.049387.

125. Wu M-C, Chin K-C, Lin K-H, Chiu N-T. Diagnostic efficacy of a low-dose 32-projection SPECT 99mTc-sestamibi myocardial perfusion imaging protocol in routine practice. Nucl Med Commun. 2009;30(2):140-147. doi:10.1097/MNM.0b013e328319e65f.

126. Yoon AJ, Melduni RM, Duncan SA, Ostfeld RJ, Travin MI. The effect of beta-blockers on the diagnostic accuracy of vasodilator pharmacologic SPECT myocardial perfusion imaging. J Nucl Cardiol. 2009;16(3):358-367. doi:10.1007/s12350-009-9066-0. 
Figure S1. QUADAS assessment summary per diagnostic technique for ICA- and FFR-significant CAD
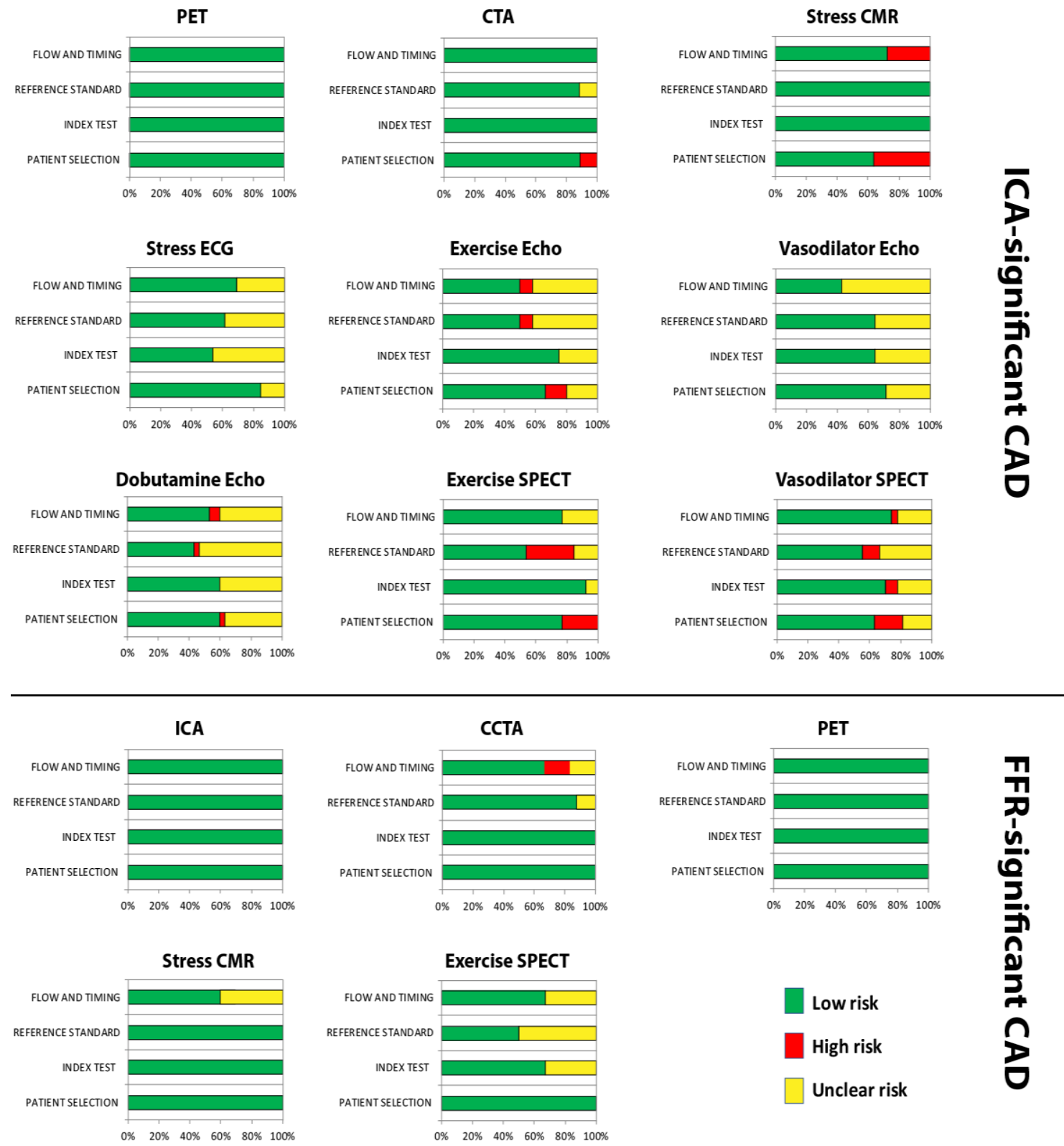
Table S4. Ranges of pre-test probability where the diagnostic techniques can confidently rule-in and rule-out anatomically or functionally significant CAD

\begin{tabular}{|c|c|c|}
\hline \multicolumn{3}{|c|}{ Pre-test probability to rule-in or rule-out Anatomically Significant CAD } \\
\hline & Prob. to Rule-Out $[95 \%$ CIs] & Prob. to Rule-In [95\% CIs] \\
\hline Stress ECG & $\leq 19[15,25]$ & $\geq 80[76,83]$ \\
\hline CCTA & $\leq 80[65,94]$ & $\geq 58[45,70]$ \\
\hline PET & $\leq 58[36,77]$ & $\geq 51[37,64]$ \\
\hline Stress CMR & $\leq 56[41,70]$ & $\geq 56[41,72]$ \\
\hline Stress ECHO & $\leq 48[40,56]$ & $\geq 56[45,67]$ \\
\hline SPECT & $\leq 47[41,53]$ & $\geq 68[63,72]$ \\
\hline \multicolumn{3}{|c|}{ Pre-test probability to rule-in or rule-out Functionally Significant CAD } \\
\hline & Prob. to Rule-Out [95\% CIs] & Prob. to Rule-In [95\% CIs] \\
\hline ICA & $\leq 27[24,31]$ & $\geq 71[59,81]$ \\
\hline CCTA & $\leq 57[40,72]$ & $\geq 75[67,83]$ \\
\hline PET & $\leq 56[43,68]$ & $\geq 50[41,58]$ \\
\hline Stress CMR & $\leq 57[48,65]$ & $\geq 46[38,54]$ \\
\hline SPECT & $\leq 34[27,41]$ & $\geq 59[47,70]$ \\
\hline
\end{tabular}


Figure S2. Simple guide to help selection of a test to detect stable CAD based on age, sex and symptoms. Table A shows the selection of a test to detect anatomic ICA-defined CAD and table B, FFR-defined CAD. Examples: In a 55year old male patient with atypical angina CCTA, SPECT, PET and stress CMR can reliably rule-out anatomically significant CAD but stress ECG or stress echocardiography cannot (A). To assess the performance of imaging tests to detect functionally significant CAD (assessed by FFR) in the same patient (B) one can see that PET and stress CMR results can both rule-out and rule-in significant CAD while CCTA can only confidently rule-out if a negative result is documented. ICA and SPECT are not recommended tests in this patient. No data about Stress ECG and stress echocardiography was available against FFR. Note: the guide table is based on the 2013 ESC SCAD Guidelines and may be subject to change when the pre-test probabilities are updated. Abbreviations: SCAD, stable coronary artery disease; CMR, stress cardiac magnetic resonance; CT, coronary computed tomography angiography; ECG, stress electrocardiogram; Echo, stress echocardiogram; FFR, fractional flow reserve; ICA, invasive coronary angiography; PET, positron emission tomography; SPECT, single photon emission computed tomography.

\section{A Utility of non-invasive tests for detection of SCAD by ICA}

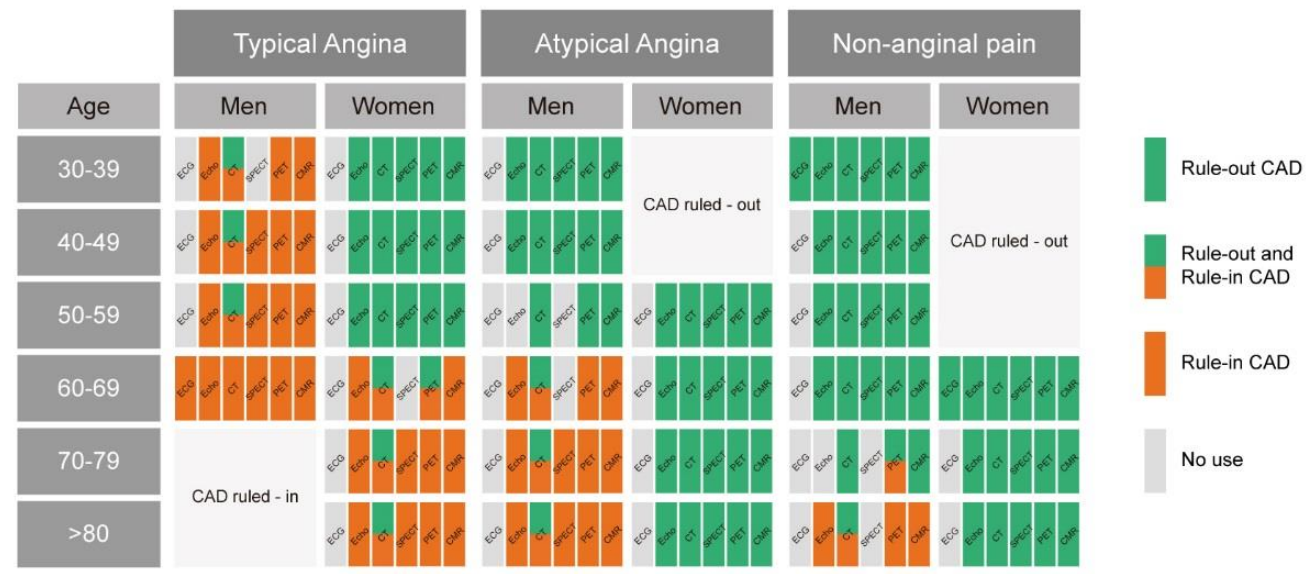

\section{B Utility of non-invasive for detection of SCAD by FFR}

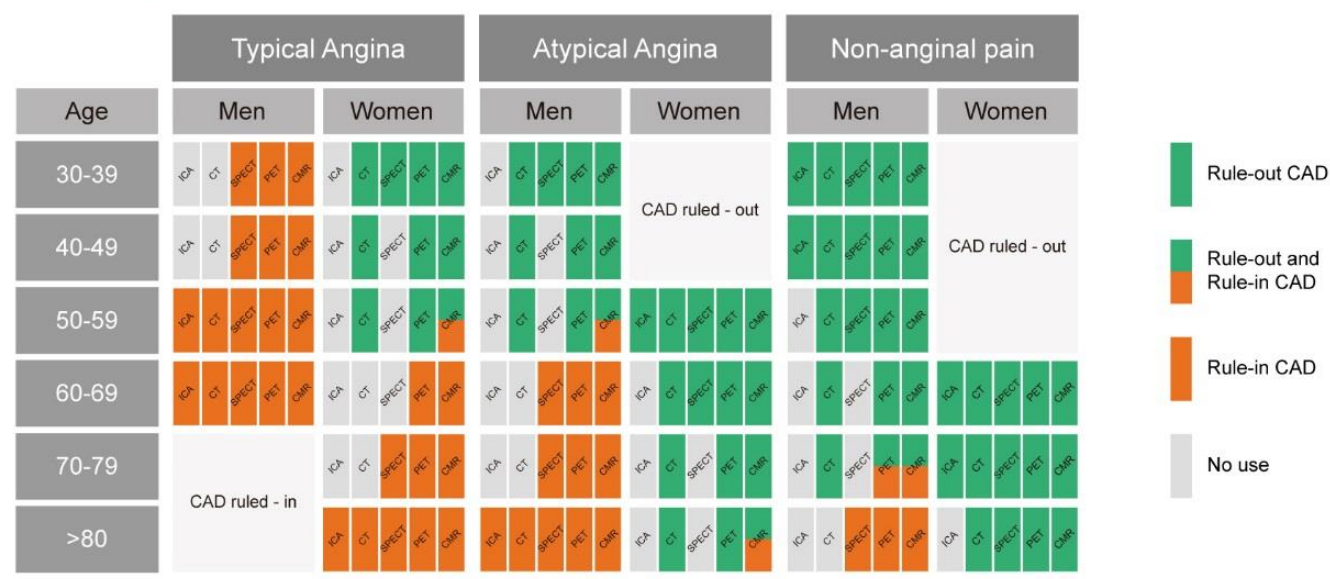

